\title{
BMJ Global Health The cost-effectiveness of hypertension management in low-income and middle-income countries: a review
}

\author{
Deliana Kostova (D , , ${ }^{1}$ Garrison Spencer, ${ }^{2}$ Andrew E Moran, ${ }^{3,4}$ Laura K Cobb, ${ }^{3}$ \\ Muhammad Jami Husain, ${ }^{1}$ Biplab Kumar Datta, ${ }^{1}$ Kunihiro Matsushita, ${ }^{5}$ \\ Rachel Nugent ${ }^{2}$
}

\begin{abstract}
To cite: Kostova D, Spencer G, Moran AE, et al. The costeffectiveness of hypertension management in low-income and middle-income countries: a review. BMJ Global Health 2020;5:e002213. doi:10.1136/ bmjgh-2019-002213
\end{abstract}

Handling editor Lei Si

- Additional material is published online only. To view please visit the journal online (http://dx.doi.org/10.1136/ bmjgh-2019-002213).

Received 9 December 2019 Revised 31 May 2020 Accepted 15 June 2020
Check for updates

(c) Author(s) (or their employer(s)) 2020. Re-use permitted under CC BY-NC. No commercial re-use. See rights and permissions. Published by BMJ.

For numbered affiliations see end of article.

Correspondence to Dr Deliana Kostova; Kiv0@cdc.gov

\section{ABSTRACT}

Hypertension in low-income and middle-income countries (LMICS) is largely undiagnosed and uncontrolled, representing an untapped opportunity for public health improvement. Implementation of hypertension control strategies in low-resource settings depends in large part on cost considerations. However, evidence on the cost-effectiveness of hypertension interventions in LMICs is varied across geographical, clinical and evaluation contexts. We conducted a comprehensive search for published economic evaluations of hypertension treatment programmes in LMICs. The search identified 71 articles assessing a wide range of hypertension intervention designs and cost components, of which 42 studies across 15 countries reported estimates of cost-effectiveness. Although comparability of results was limited due to heterogeneity in the interventions assessed, populations studied, costs and study quality score, most interventions that reported cost per averted disability-adjusted lifeyear (DALY) were cost-effective, with costs per averted DALY not exceeding national income thresholds.

Programme elements that may reduce cost-effectiveness included screening for hypertension at younger ages, addressing prehypertension, or treating patients at lower cardiovascular disease risk. Cost-effectiveness analysis could provide the evidence base to guide the initiation and development of hypertension programmes.

\section{INTRODUCTION}

Hypertension in low-income and middleincome countries (LMICs) remains largely undiagnosed, untreated and uncontrolled despite being a leading factor in preventable death and disability (Chow et al, 2013 ${ }^{1}$; Ibrahim and Damasceno, 2012 ${ }^{2}$; Lozano et al, 2018 ${ }^{3}$; and WHO, 2013 ${ }^{4}$. The suboptimal treatment of hypertension in LMICs represents an untapped opportunity for public health improvement (Frieden and Bloomberg, 2018). ${ }^{5}$ Recent estimates suggest that nearly 40 million hypertension-related deaths can be avoided over the next 25 years

\section{Key questions}

What is already known?

- Implementation of hypertension control strategies in low-resource settings depends in large part on cost considerations, but evidence on the costeffectiveness of hypertension interventions from low-income and middle-income countries (LMICs) is sparse and varied across geographical, clinical and evaluation contexts.

\section{What are the new findings?}

- Most interventions that reported cost per averted disability-adjusted life-year were cost-effective using national income thresholds, but gaps in evidence exist on programme elements that can affect cost-effectiveness in LMICs, such as task-sharing, risk-based treatment and standardised treatment protocols.

What do the new findings imply?

- Hypertension control is found to be a cost-effective intervention for many LMICs. Gaps in evidence can be filled by economic evaluation of programme elements that include shifting some healthcare tasks to non-physician providers, integrating cardiovascular disease (CVD) risk assessment into treatment decisions and incorporating standardised CVD prevention programmes.

by scaling up hypertension treatment to $70 \%$ (Kontis et al, 2019). ${ }^{6}$

Hypertension management depends on consistent and reliable access to healthcare. Areas with documented shortages of healthcare workers and with limited access to formal healthcare, such as sub-Saharan Africa, have fared the worst in addressing hypertension (Geldsetzer et al, 2019). ${ }^{7}$ At the population level, weak hypertension control and insufficient cardiovascular disease (CVD) prevention in LMICs can have broad implications that exceed the direct health consequences. For example, clustering of hypertension-related 
disease in younger adults, which is disproportionately more common in LMICs than high-income countries (Roth et al, 2018), ${ }^{8}$ has considerable socioeconomic effects, contributing to productivity and income losses at the household level and impeding macroeconomic growth (Bloom et al, 2011). ${ }^{9}$

While the value of addressing hypertension in LMICs has gained recognition over the past decade, resources in this area remain limited, revealing a gap between health targets and current needs (United Nations (UN), $2011^{10}$;UN, $2015^{11}$; and WHO, 2018 $\mathrm{a}^{12}$ ). The transition from goal setting to actual implementation of hypertension control strategies in LMICs depends in large part on cost considerations. Although some economic modelling suggests that both population-level and clinical interventions for hypertension control can be costeffective (Murray et al, 2003 ${ }^{13}$; Jha et al, 2012 ${ }^{14}$; Nugent and Brouwer, 2015 ${ }^{15}$; Bertram et al, 2018 ${ }^{16}$; and WHO, $2018 b^{17}$ ), policymakers in individual countries might regard aggregate global estimates to be insufficient evidence for policy formulation in specific country circumstances. To inform policy decisions regarding hypertension approaches in LMICs, we reviewed the current evidence on costs and cost-effectiveness of hypertension interventions across LMICs. The contribution of this study is twofold. First, it provides the first comprehensive review of the evidence on cost-effectiveness of hypertension management programmes in LMICs. This review summarises the available evidence most relevant to policymakers in countries where hypertension management is currently limited or absent, and where decision-makers may be considering additions to health benefit packages without detailed cost or cost-effectiveness information. Second, this review documents the variation among existing studies across study designs and study quality. It produces a standardised quality score and explores contextual differences such as those that may arise between programmes based exclusively on pharmaceutical intervention and programmes that incorporate nonpharmaceutical components; programmes that target hypertension populations with different levels of CVD risk; or programmes applied in countries with different income levels. This too provides informative evidence to decision-makers in LMICs. The results describe a range of clinical programmes and corresponding programme cost and cost-effectiveness estimates from different settings, with varying levels of quality. We found gaps in evidence on programme elements that can affect costeffectiveness in LMICs, such as shifting of healthcare tasks to non-physician providers, integrating CVD risk assessment into treatment decisions and standardising CVD prevention approaches.

\section{Patient and public involvement}

No patients or human subjects were involved in the process of conducting this literature review.

\section{METHODS}

In March 2019, we searched for articles on economic evaluation of hypertension treatment programmes in LMICs using PubMed, the Cochrane Collaboration Database of Systematic Reviews, the Tufts Cost-Effectiveness Analysis Registry, the UK's National Institute for Health and Care Excellence (NICE) guidelines, the University of York Centre for Reviews and Dissemination and the Disease Control Priorities ( $3^{\text {rd }}$ Edition). To guide the search eligibility criteria, we developed a PICOTS table summarising the inclusion and exclusion criteria across the following elements: population, intervention, comparator, outcomes, time frame, settings and study design (Liberati et al, 2009) ${ }^{18}$ (see online supplementary appendix table A1). The search was performed using Medical Subject Headings $(\mathrm{MeSH})$ and search terms related to hypertension and the pharmacological treatment, diagnosis, screening and management of hypertension. The list of MeSH terms can be found in online supplementary appendix table A2. We also used search terms for world regions; all low-income, lower middleincome and upper middle-income country names; newly classified high-income countries in South America, the Caribbean and the Pacific; and economic terms related to costs and cost-effectiveness. The PubMed search strategy can be found in online supplementary appendix table A3. We performed a supplemental ad hoc literature scan without MeSH terms in May 2020 to account for the lag in indexing and to capture any recent articles. The initial search identified 60 articles for inclusion in the review while the supplemental scan identified an additional 11 relevant publications. Results were not limited by publication date.

An inclusion/exclusion guide was created for reviewing the abstracts and full-text of articles (see online supplementary appendix table A4). Articles were included if they involved an intervention related to clinical screening, treatment and management of hypertension. Articles were excluded if they were designed for other diseases for which hypertension may be a risk factor or common comorbidity, or if they were for surgery patients to address acute events related to hypertension. Articles were excluded if they looked only at the cost of hypertension, with no reference to a specific intervention; only studied the prevalence of hypertension; if they did not involve any clinical setting; or, if they studied knowledge or awareness of hypertension. Studies that were conducted in high-income countries, or in territories or associated states of high-income countries (with the exception of South America, the Caribbean and the Pacific), studies that were published in a foreign language, and any article that was an editorial, review, correspondence or abstract related to study design and protocol were also excluded.

Overall, 595 references were identified: 534 from PubMed and 61 from other databases and sources. Screening abstracts identified 163 articles for full-text review of which 71 were identified as relevant for inclusion in the analysis (see online supplementary appendix 


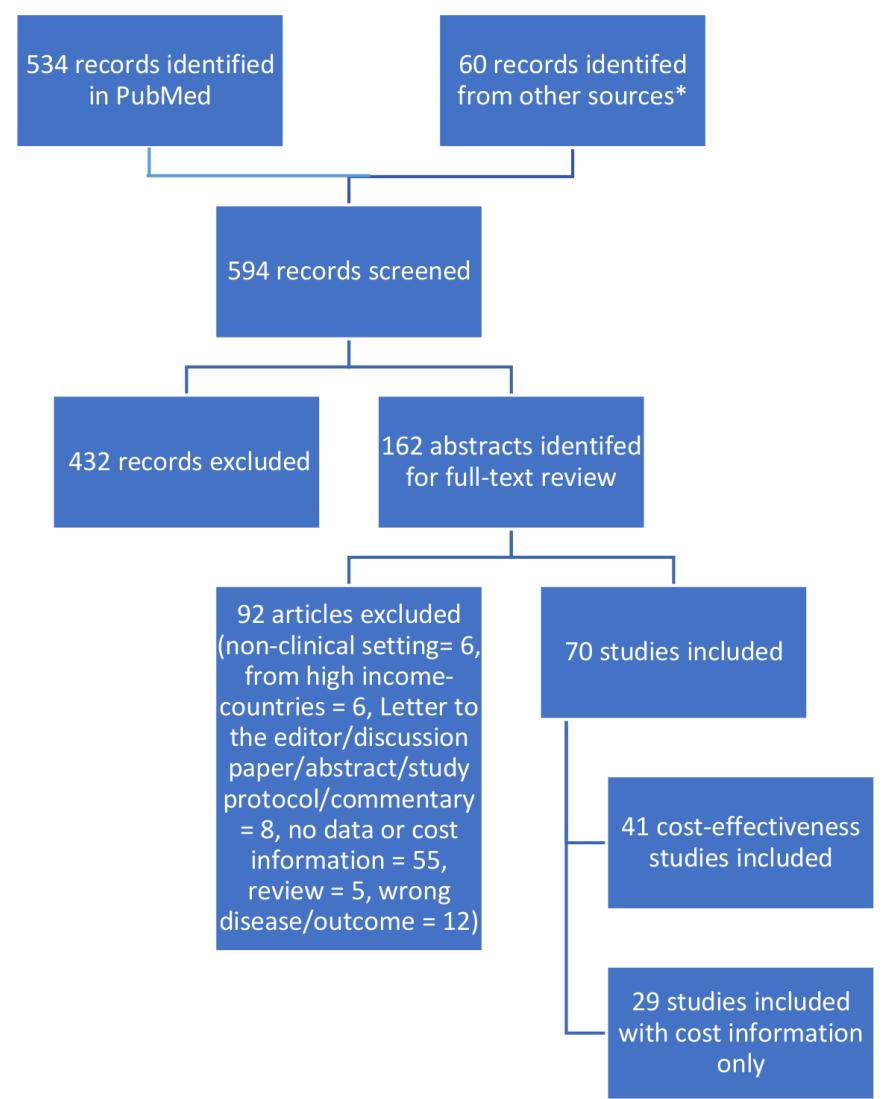

Figure 1 Summary diagram of the costs and costeffectiveness literature search process. *Other sources searched include the Cochrane Collaboration Database of Systematic Reviews, the Tufts Cost-Effectiveness Analysis Registry, the UK's National Institute for Health and Care Excellence (NICE) guidelines, the University of York Centre for Reviews and Dissemination and the Disease Control Priorities ( $3^{\text {rd }}$ Edition). These databases were hand searched using similar terms as the PubMed search strategy found in online supplementary appendix table A3.

table A5). Of these, 42 studies across 15 countries provided estimates of cost-effectiveness, with the rest evaluating costs only. A diagram of the search process is depicted in figure 1. Each of the 42 cost-effectiveness studies underwent a quality assessment based on a 13-question checklist informed by Drummond guidelines for economic evaluation of healthcare programmes (Evers et al, 2005). ${ }^{19}$ These studies were reviewed and assigned a total score equal to the sum of positive answers to the checklist questions.

Reported indicators included: cost per $\mathrm{mm} \mathrm{Hg}$ reduction in systolic and/or diastolic blood pressure (table 1), cost per patient with controlled hypertension (table 2), cost per patient with hypertension (table 3), cost per averted disability-adjusted life year (DALY) (table 4) and cost per gained quality-adjusted life year (QALY) (table 5). Estimates were converted to constant 2017 US dollars (US\$) and were adjusted to reflect annual amounts where applicable. Two studies reported estimates in purchasing-power-parity (PPP)-adjusted international dollars, which were not converted into US\$ because appropriate conversion factors were not available for the blend of countries examined (Ortegon et $a l, 2012^{20}$ and Murray et al, 2003). Studies in the above cost-effectiveness categories were further categorised according to intervention type, as follows. 'Pharm only' indicates interventions where pharmacotherapy is the only treatment element, encompassing various combinations of drugs and drug classes, different providers and delivery platforms. 'Pharm plus' indicates combination programmes that incorporate other forms of treatment for hypertension in addition to medications, such as patient education or lifestyle changes. 'Other' indicates interventions that did not evaluate changes in pharmacological treatment. Cost elements included costs of medication, laboratory work, labour, equipment, transportation, provider training and others.

\section{RESULTS}

\section{Study characteristics}

Thirty-six of the identified studies were conducted in upper-middle-income countries (UMICs), 30 studies were from low-income and lower-middle-income countries (LLMICs) and five studies included countries of different income levels. Studies reported costs of hypertension treatment, cost-effectiveness of hypertension treatment or both. Twenty-five of the studies included only medication costs, while the remaining studies included health system costs and other services such as laboratory tests, health provider time and other screening costs. Study designs included longitudinal (seven studies), crosssectional (four studies), modelled or simulated (22 studies), randomised control trials (seven studies) and retrospective cohort studies (two studies).

After conducting the quality assessment based on the 13-question checklist informed by Drummond guidelines for economic evaluation of healthcare programmes (Evers et al, 2005), ${ }^{19}$ the average quality score of the studies was 7.8. Modelled studies and randomised control trials tended to be higher quality, with average scores of 9.6 and 8.4, respectively. Longitudinal, cross-sectional and retrospective cohort studies were lower quality, with average scores of 5.0, 4.3 and 3.0, respectively (table 6).

Fifty-four studies described pharmaceutical-only interventions using various combinations of antihypertensive drugs and drug classes. Fifteen studies assessed pharmaceutical treatment plus at least one other component, such as providing physician training, implementing treatment guidelines or offering lifestyle advice. A small number of studies did not include pharmaceutical treatment and instead assessed cost-effectiveness of activities such as physician training, lifestyle education (Bai et $a l, 2013^{21}$ and Jafar et al, 2011), ${ }^{22}$ or loaning out blood pressure self-measurement devices (Calvo-Vargas et al, 2001). ${ }^{23}$ Four different delivery platforms were represented across studies: community-based services; health centres providing basic medical care and staffed by a physician, nurse or mid-level healthcare provider; first-level 


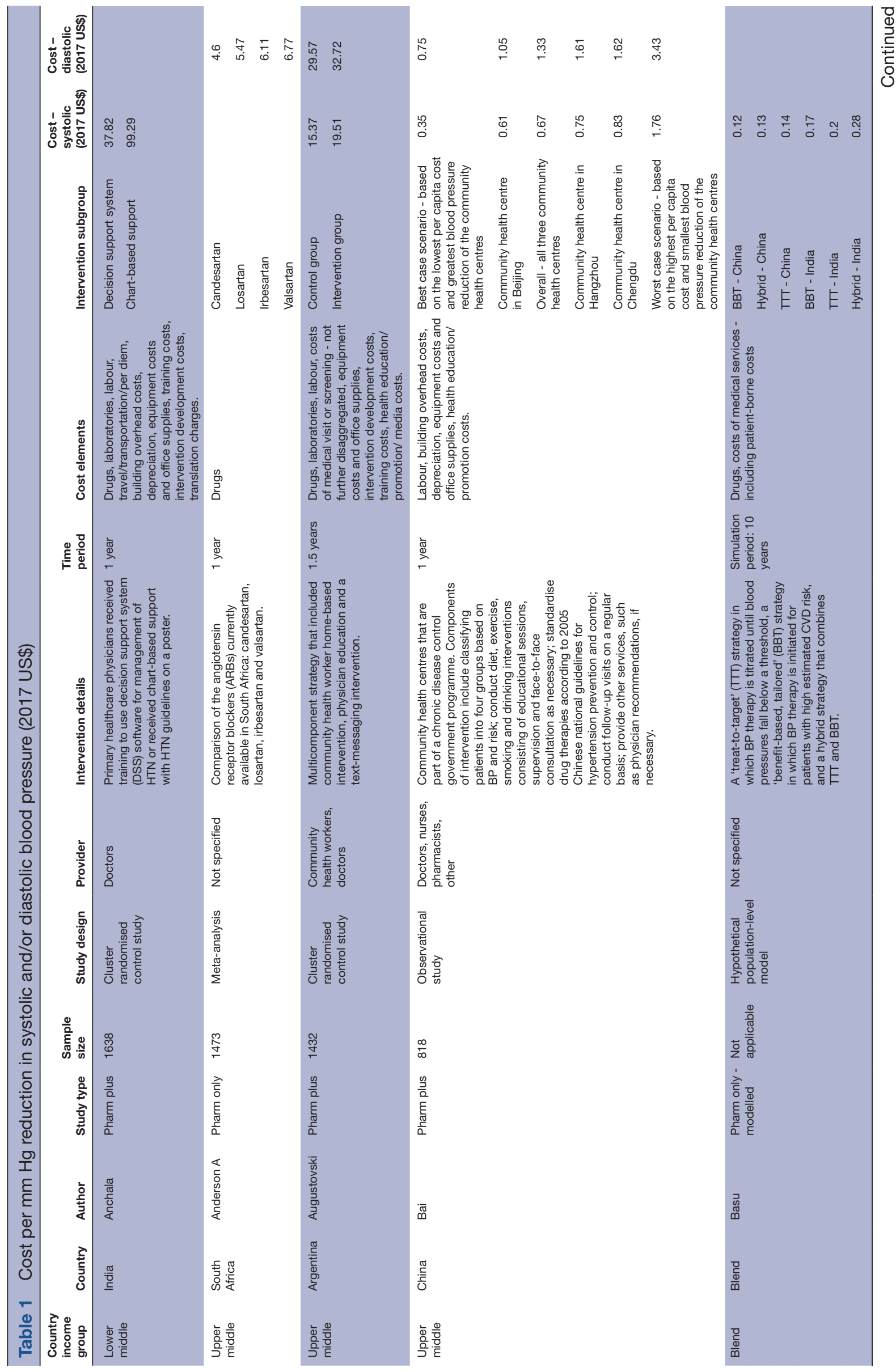




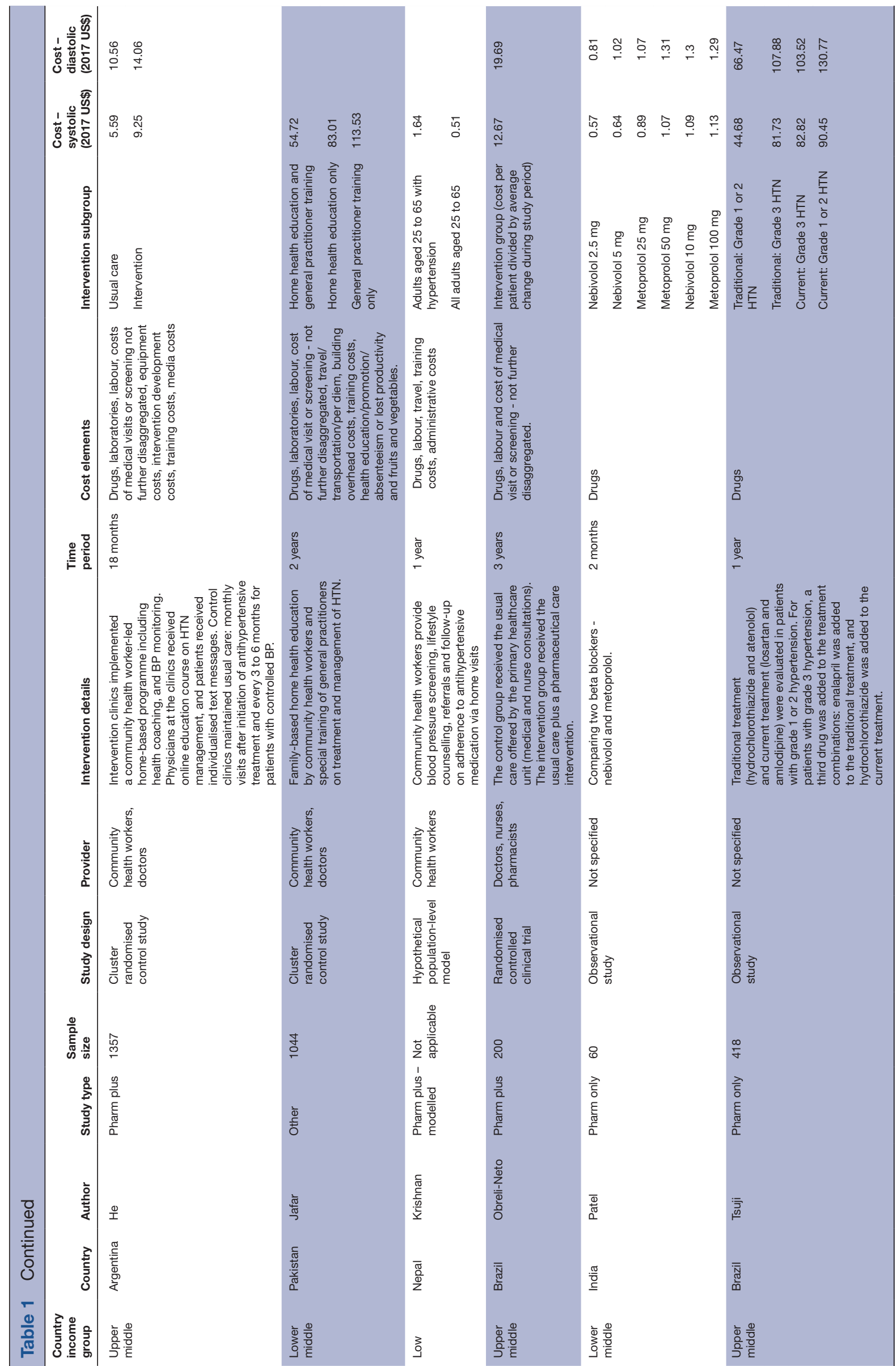

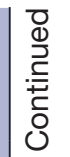




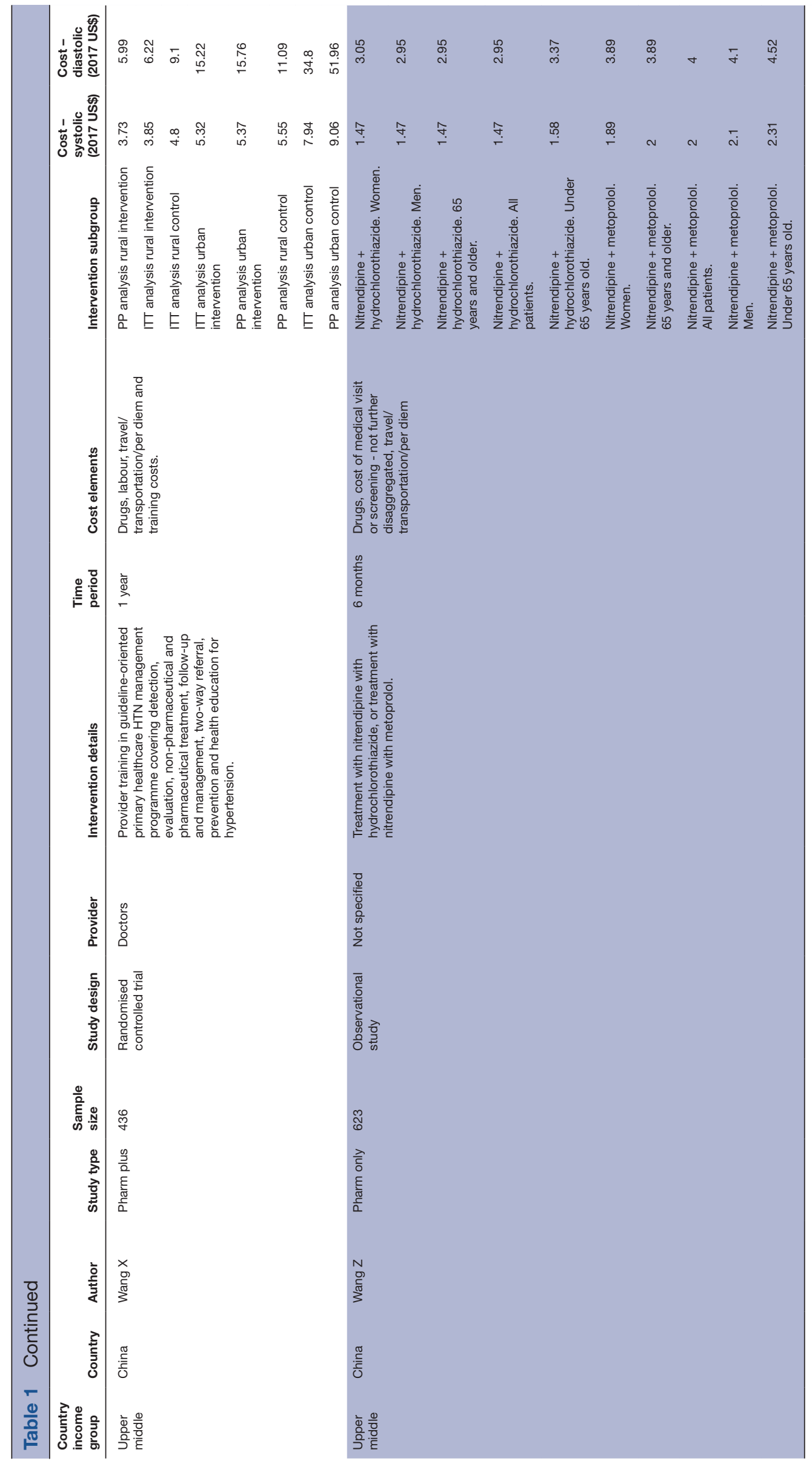

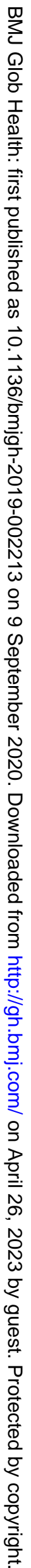




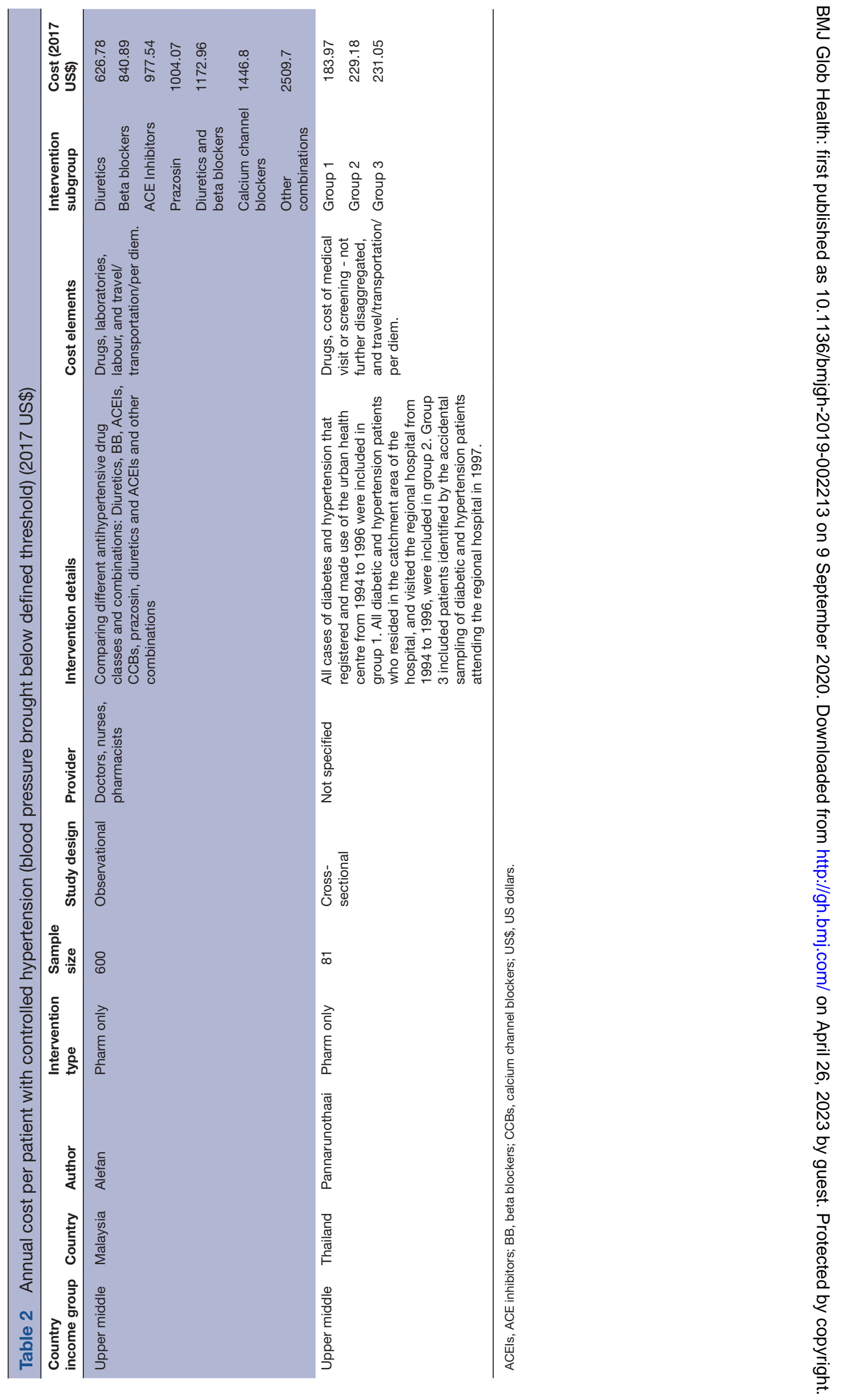




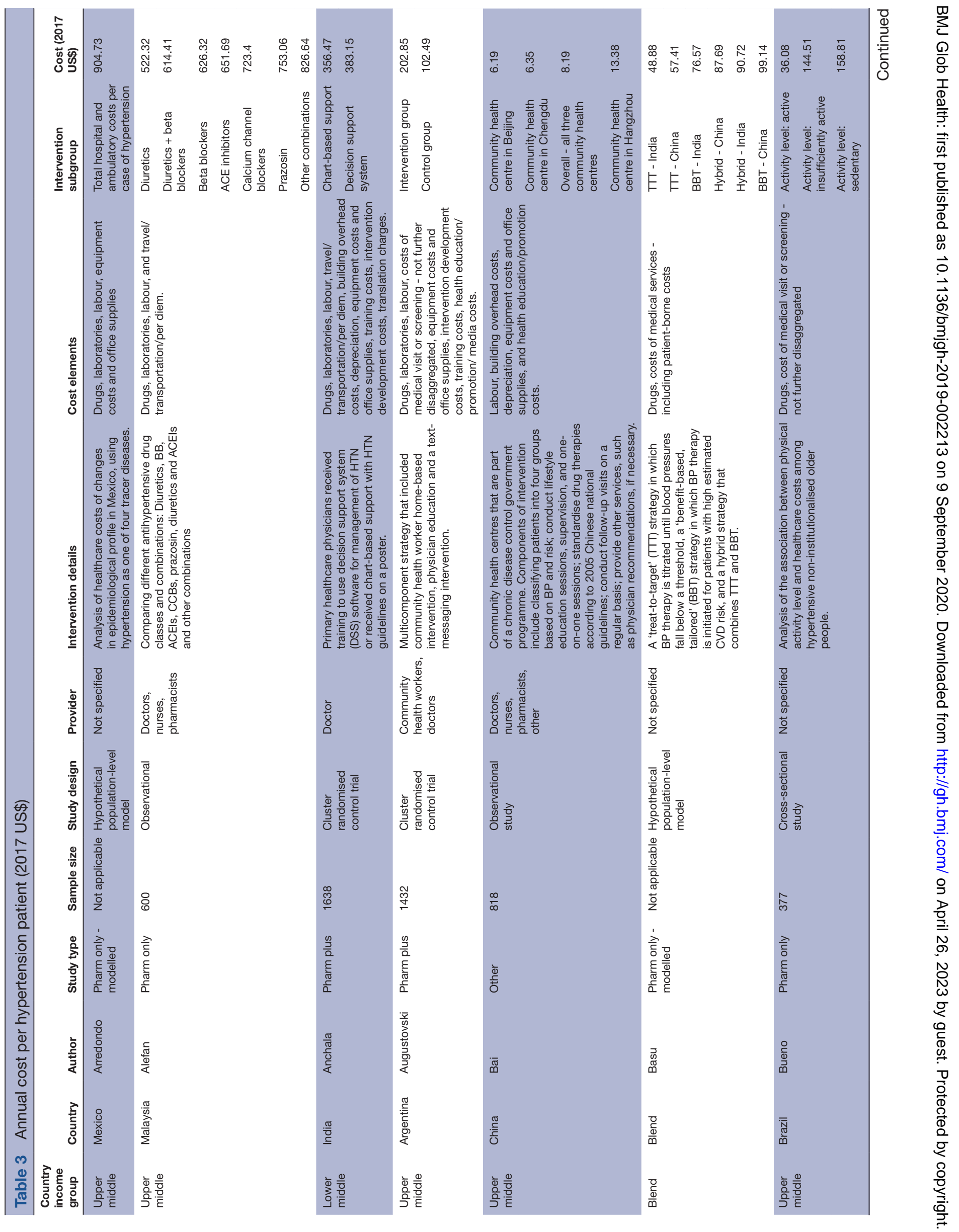




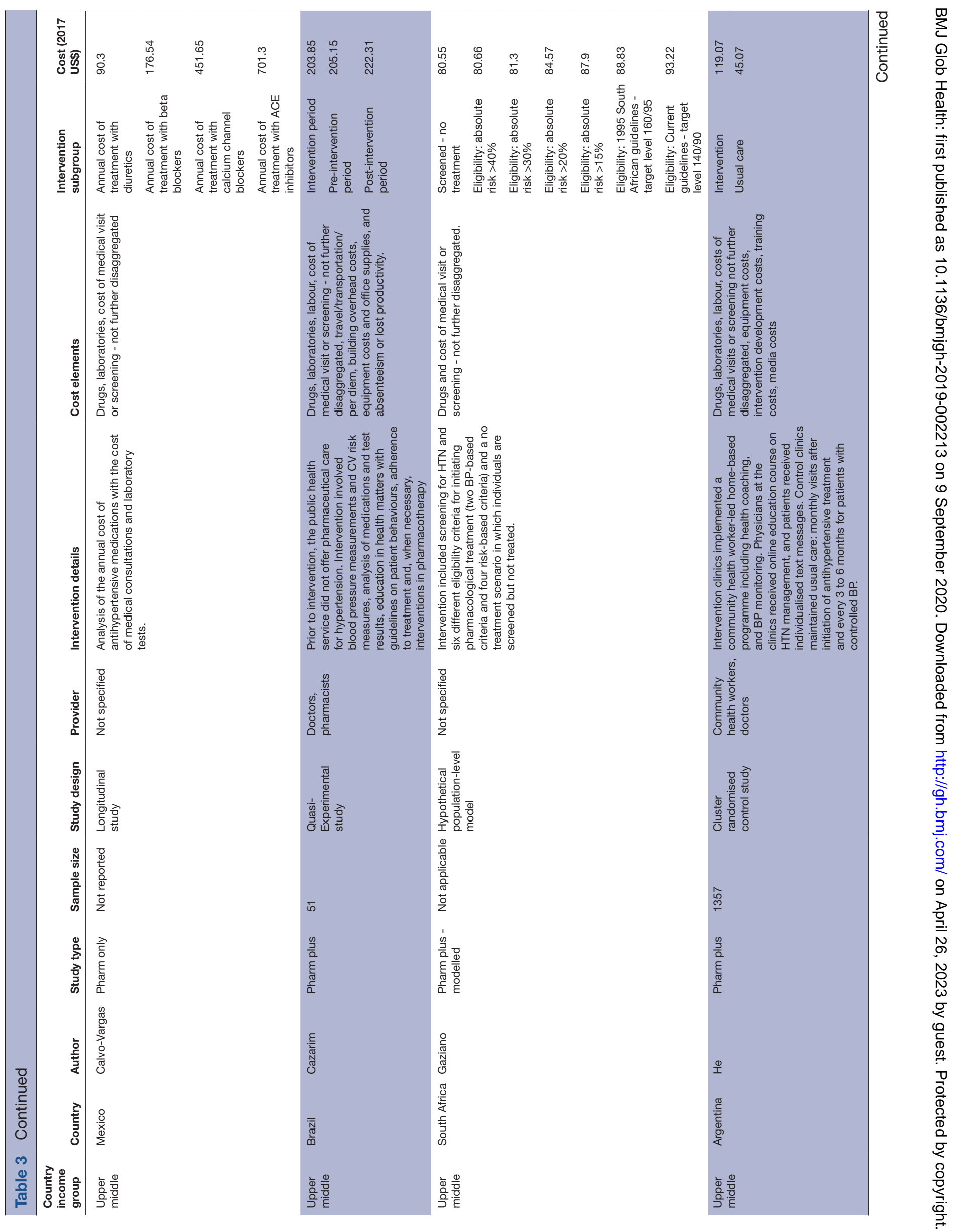




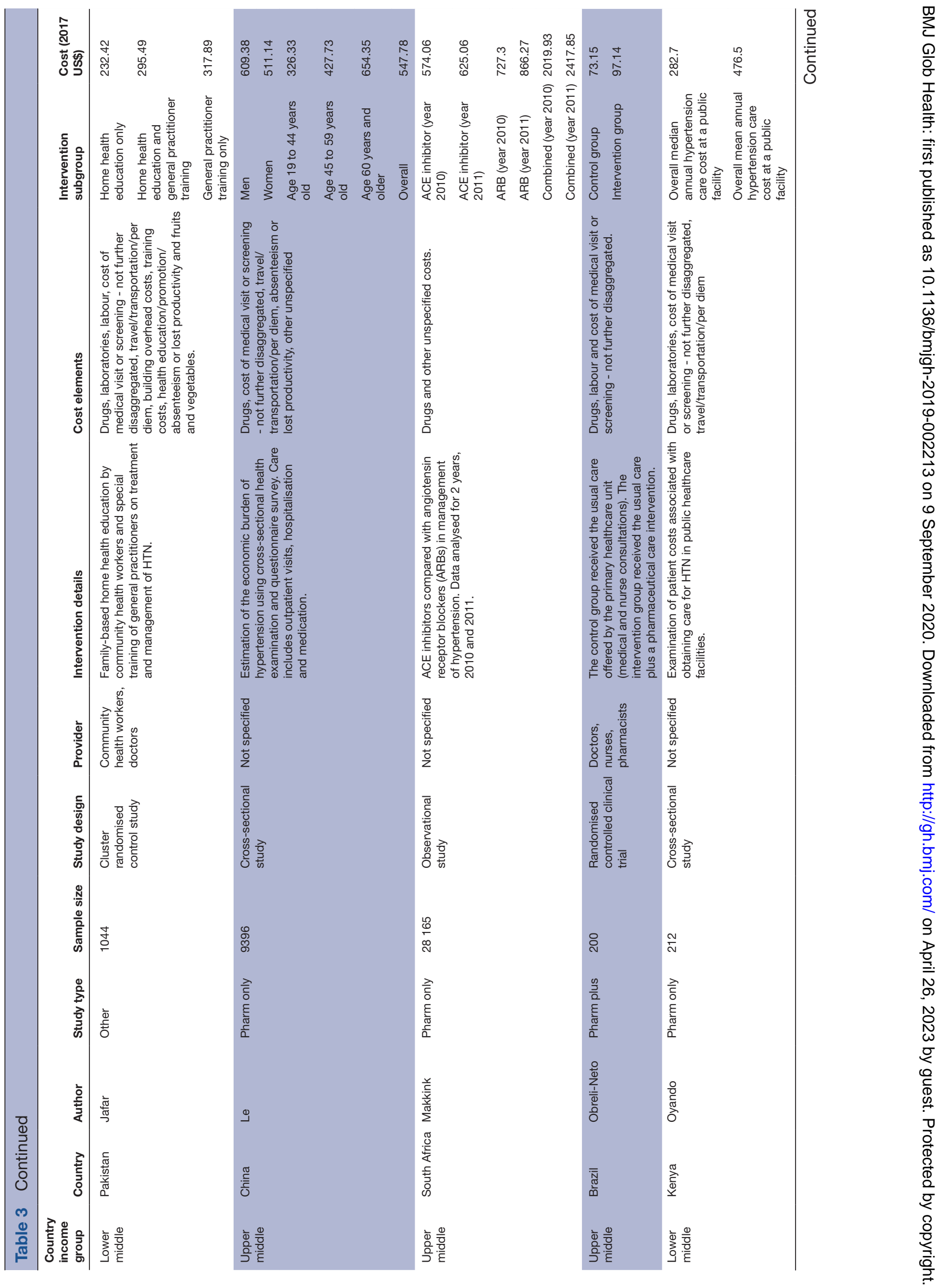




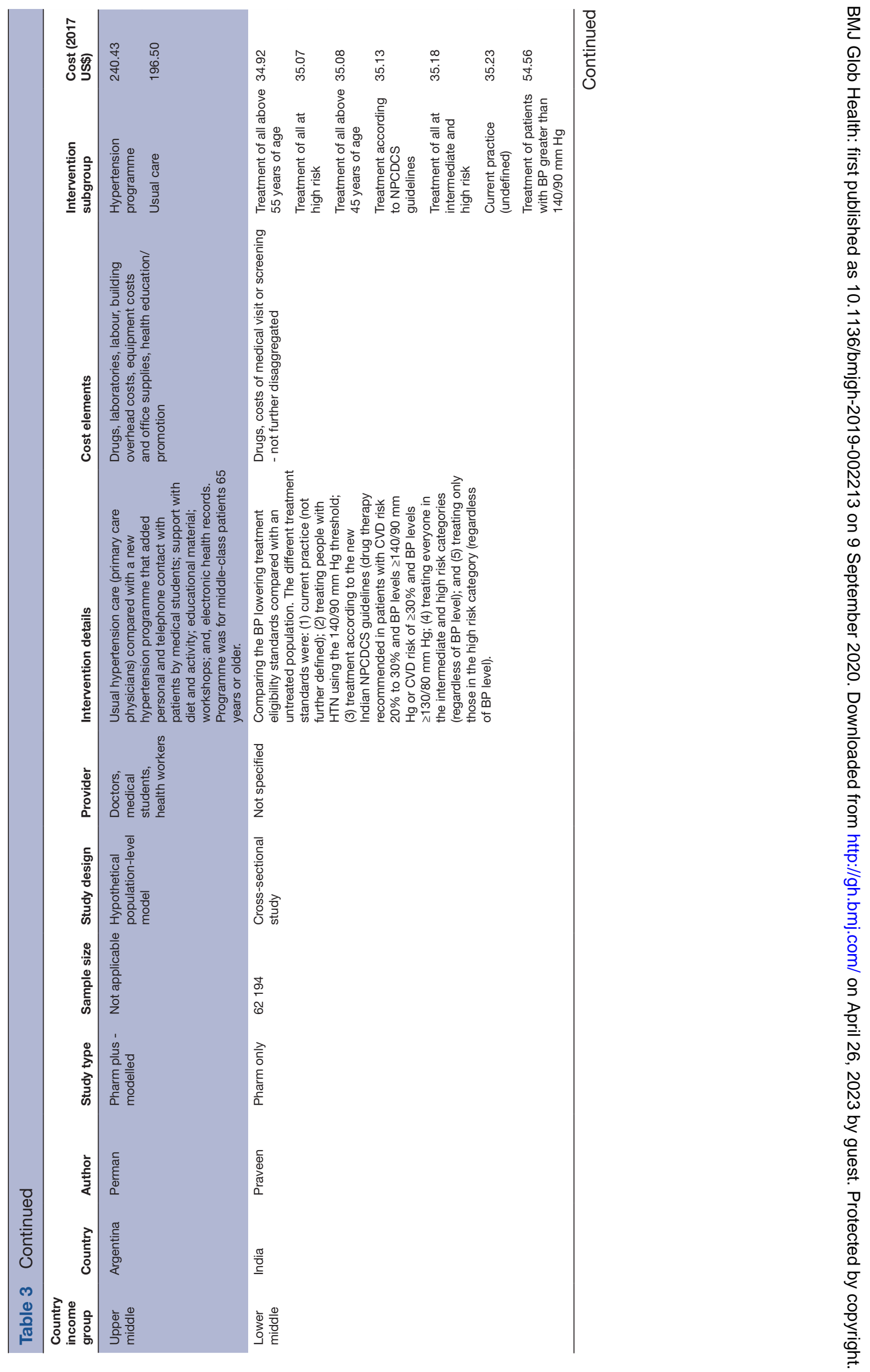




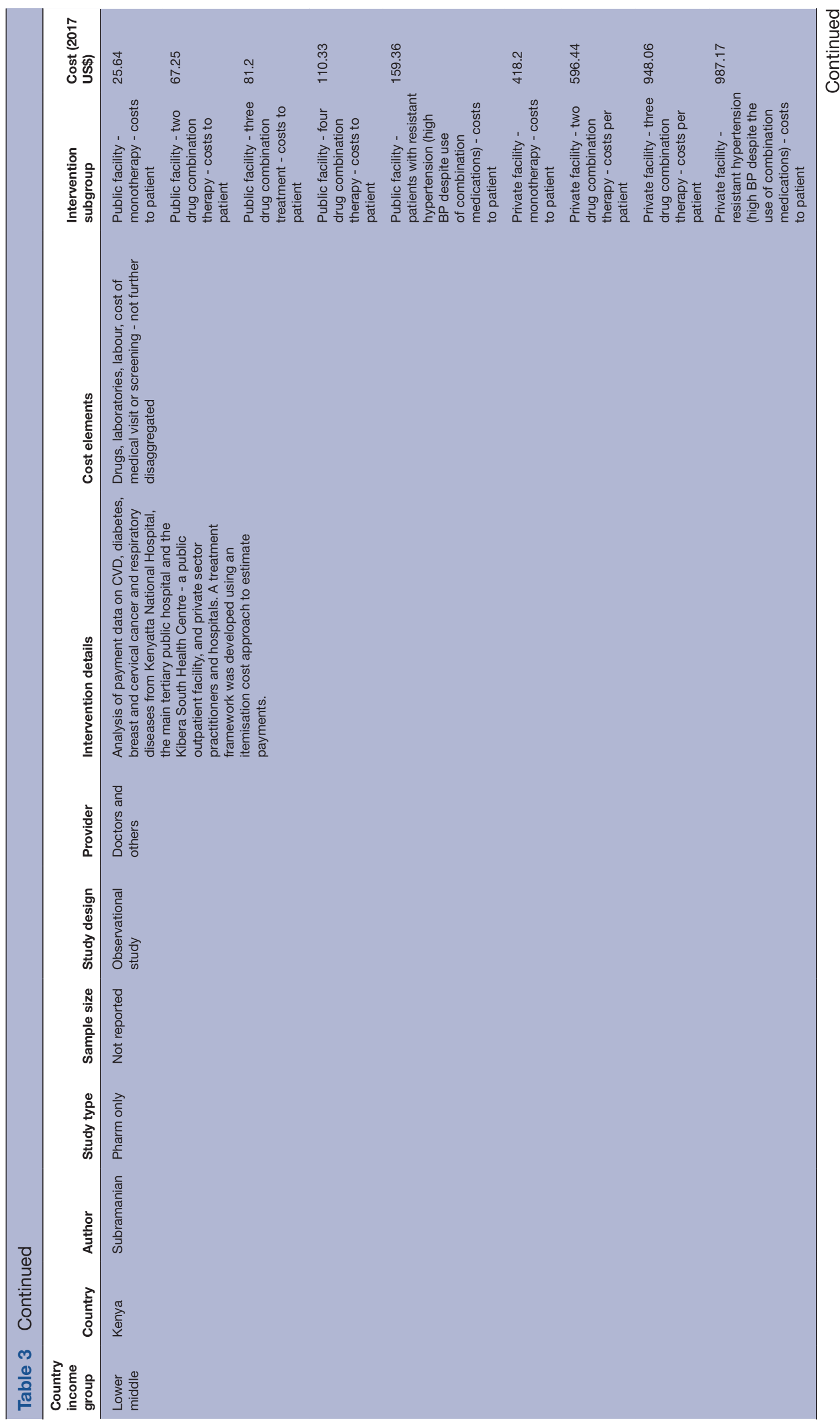

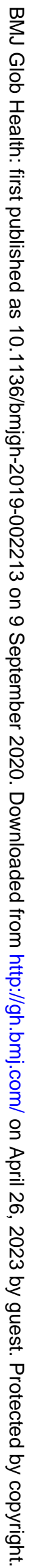




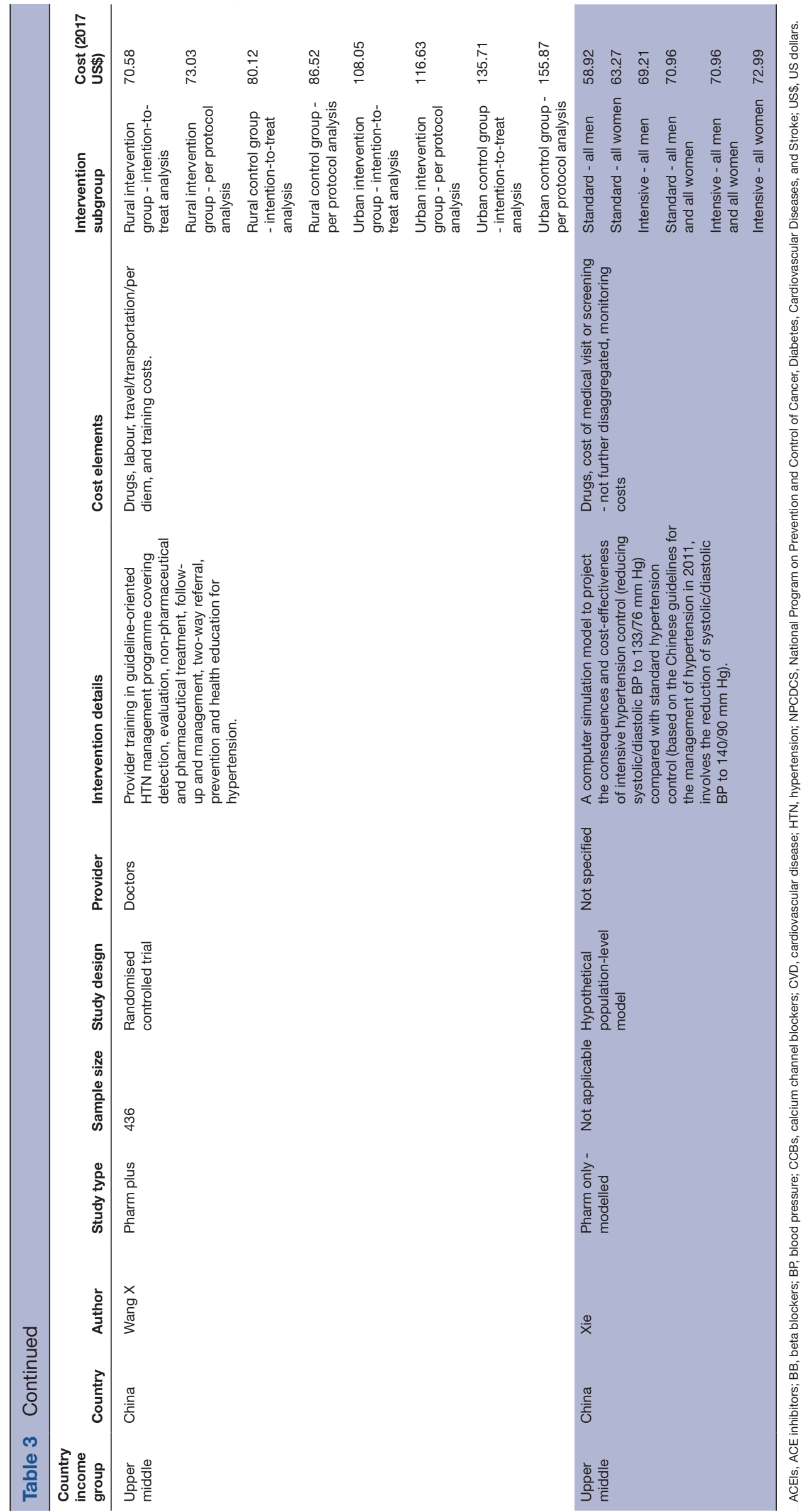




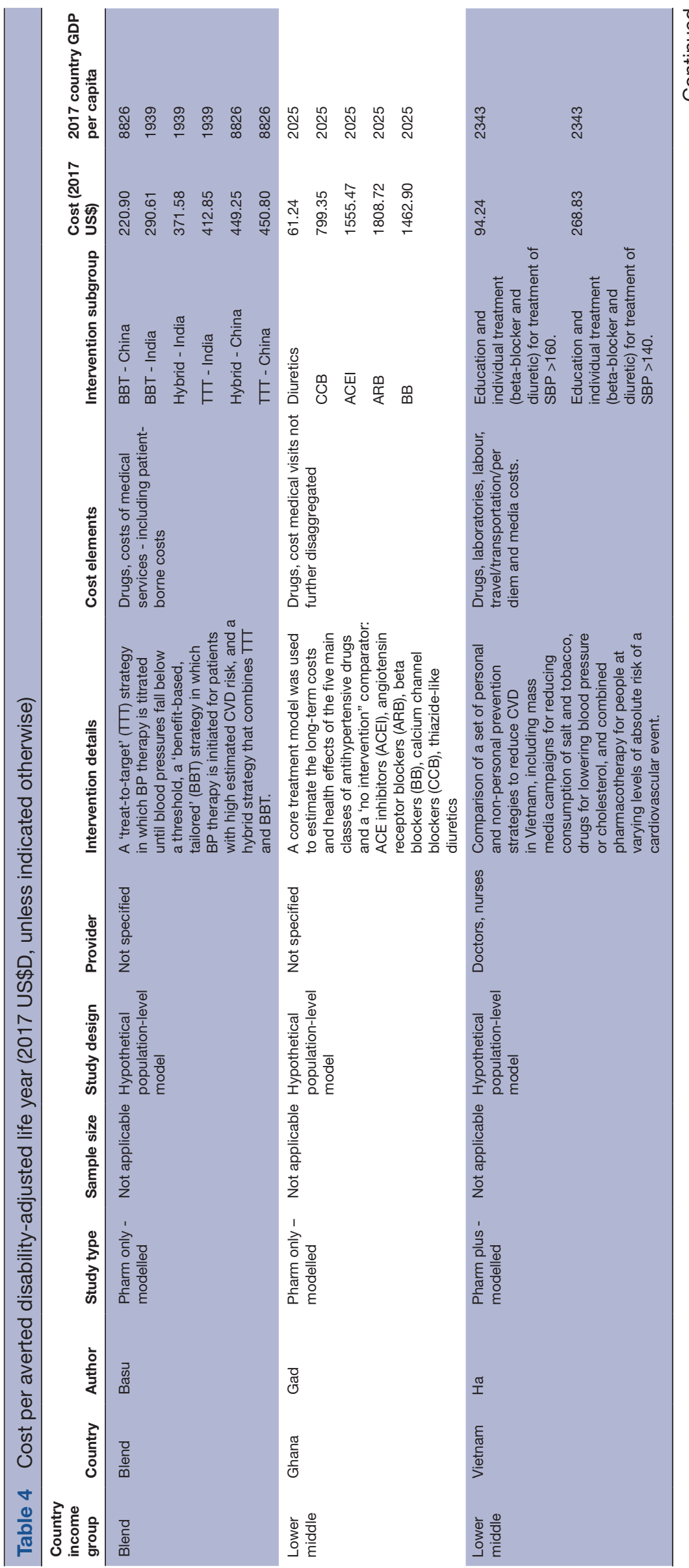




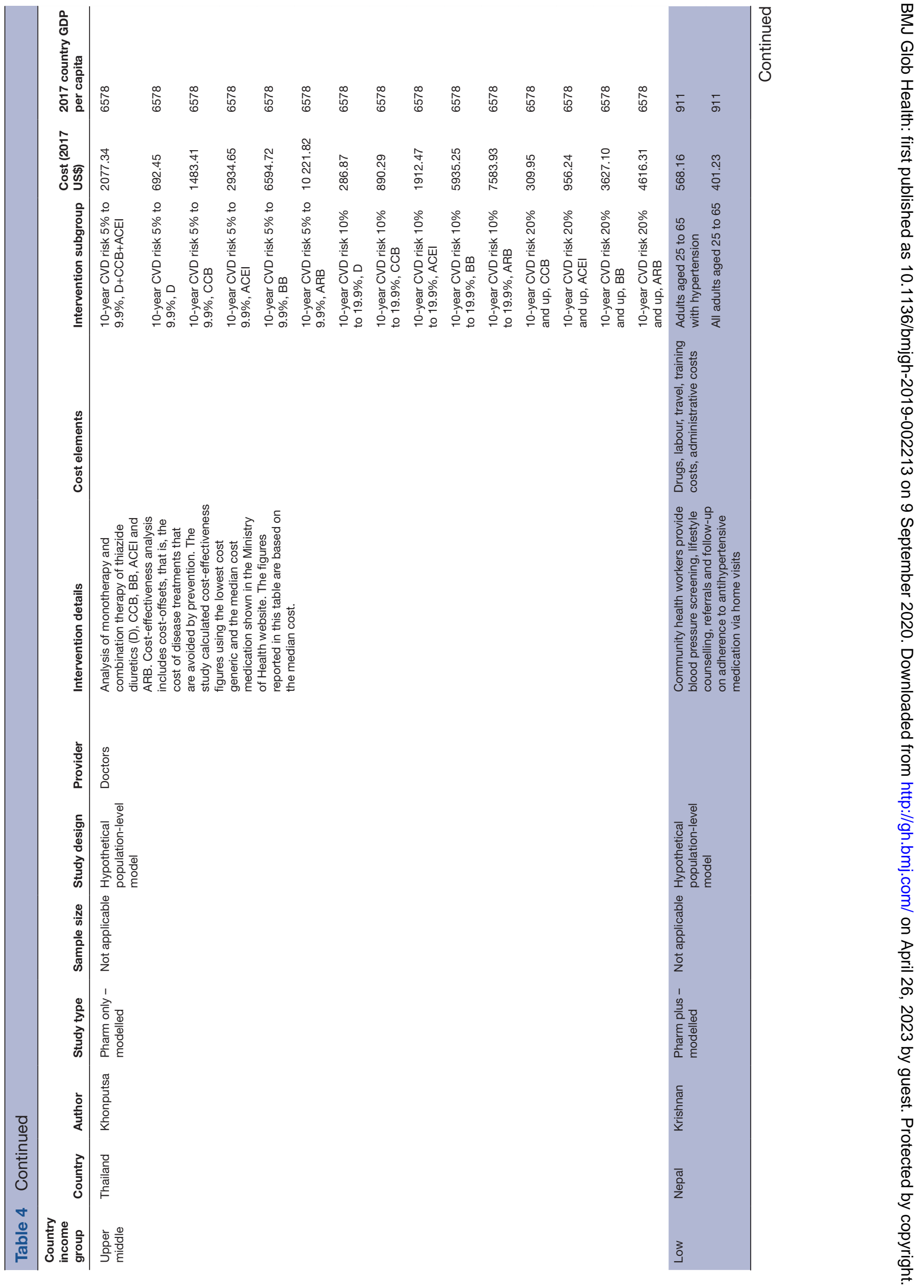




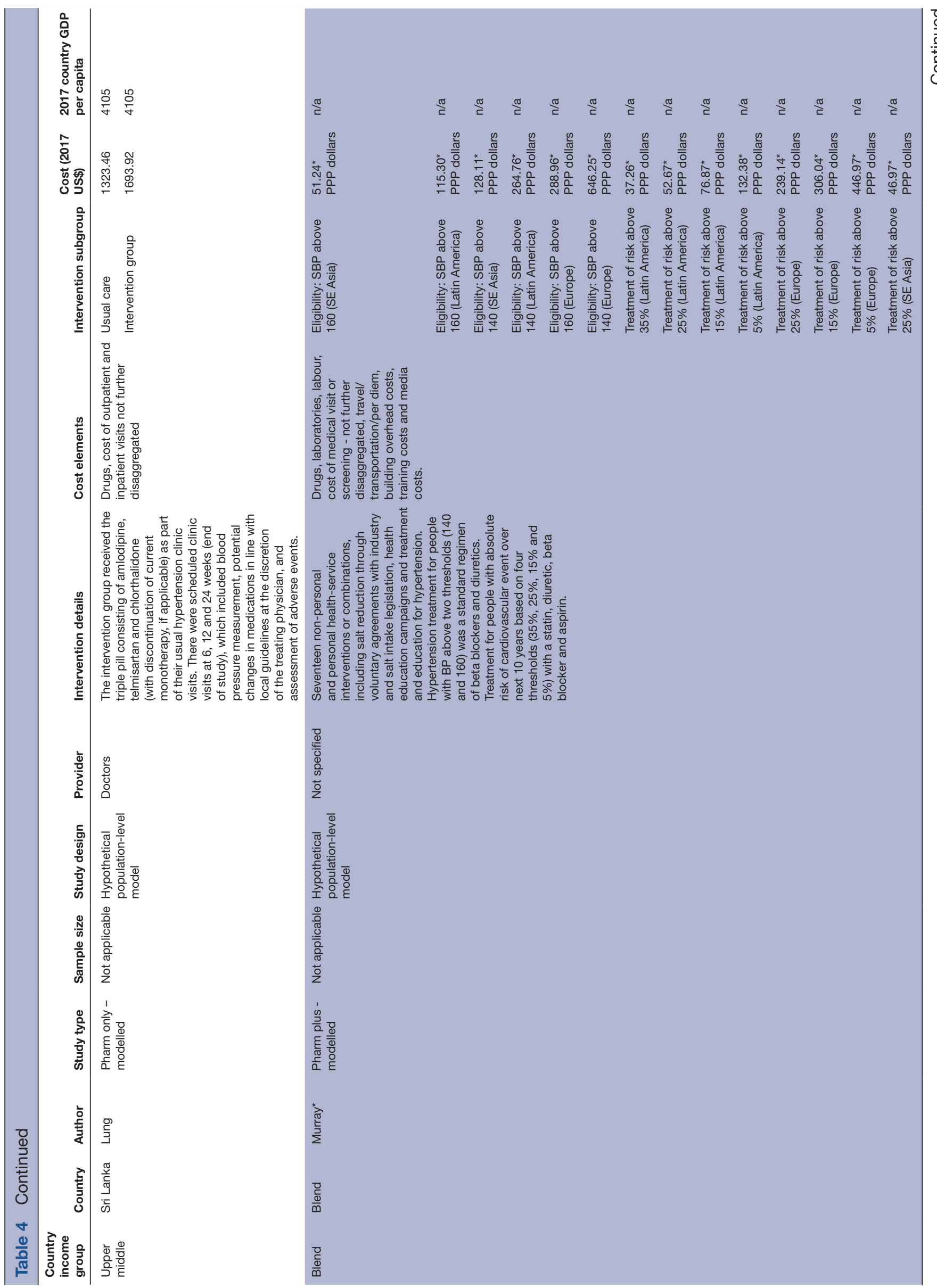



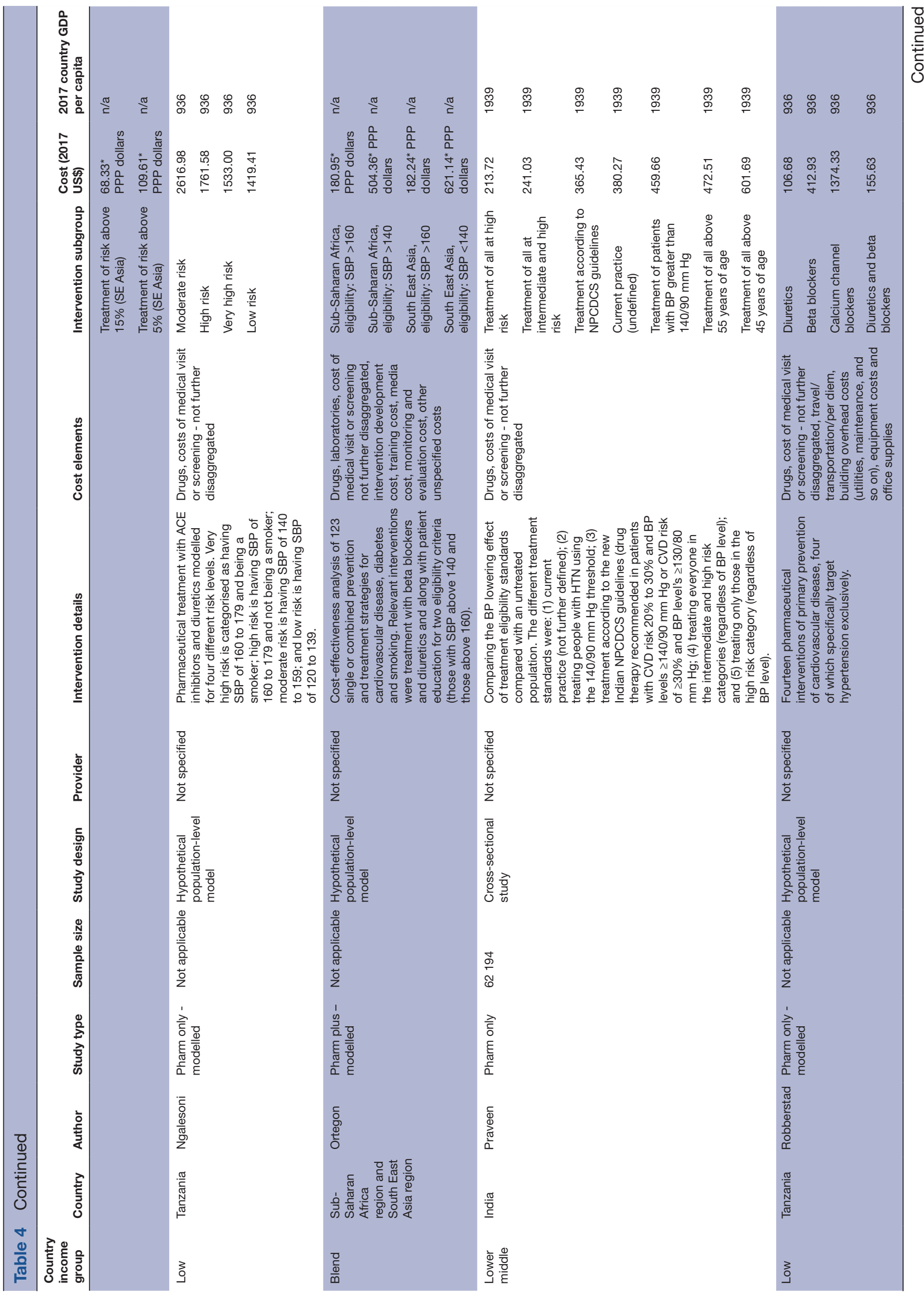


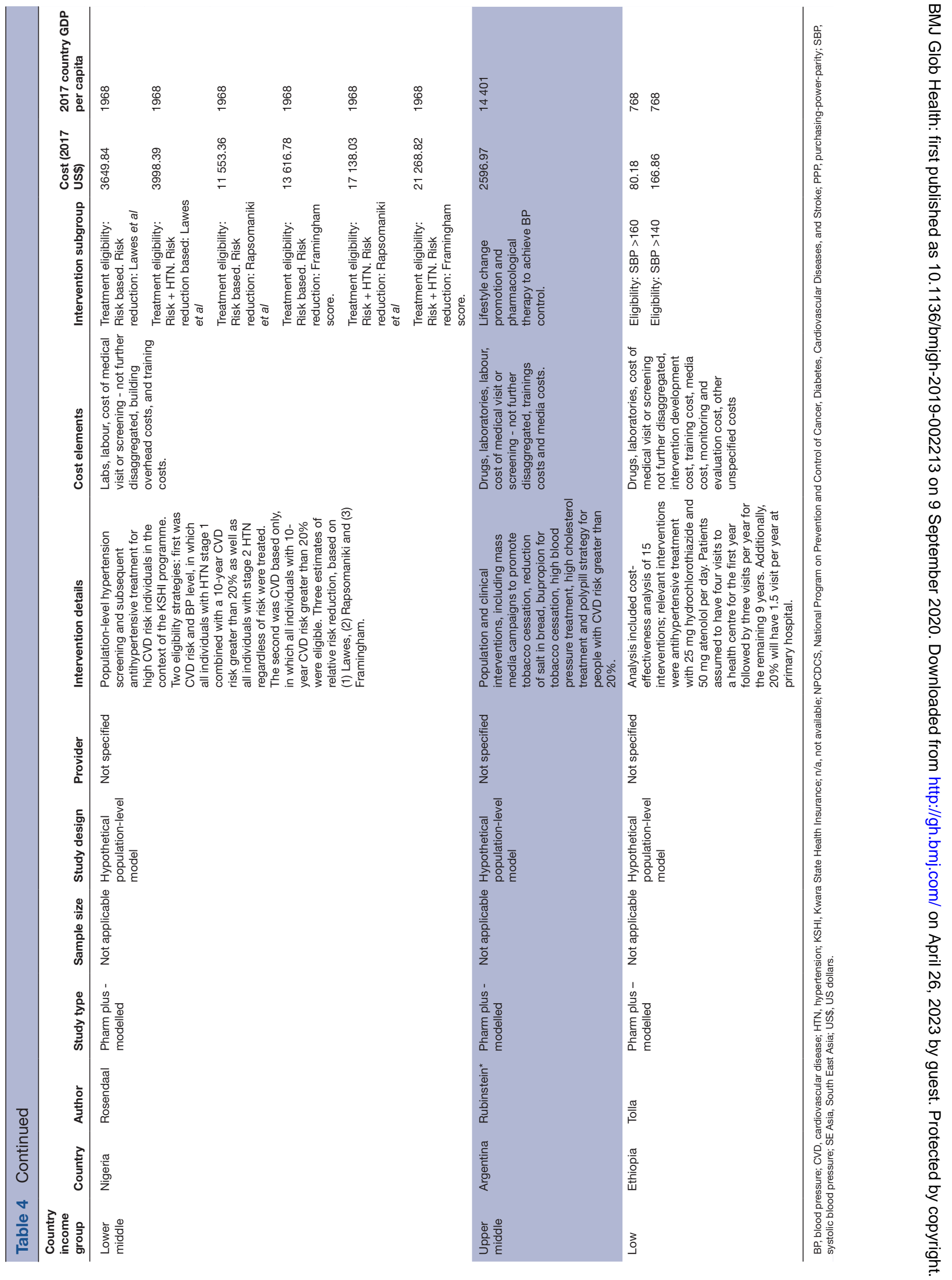




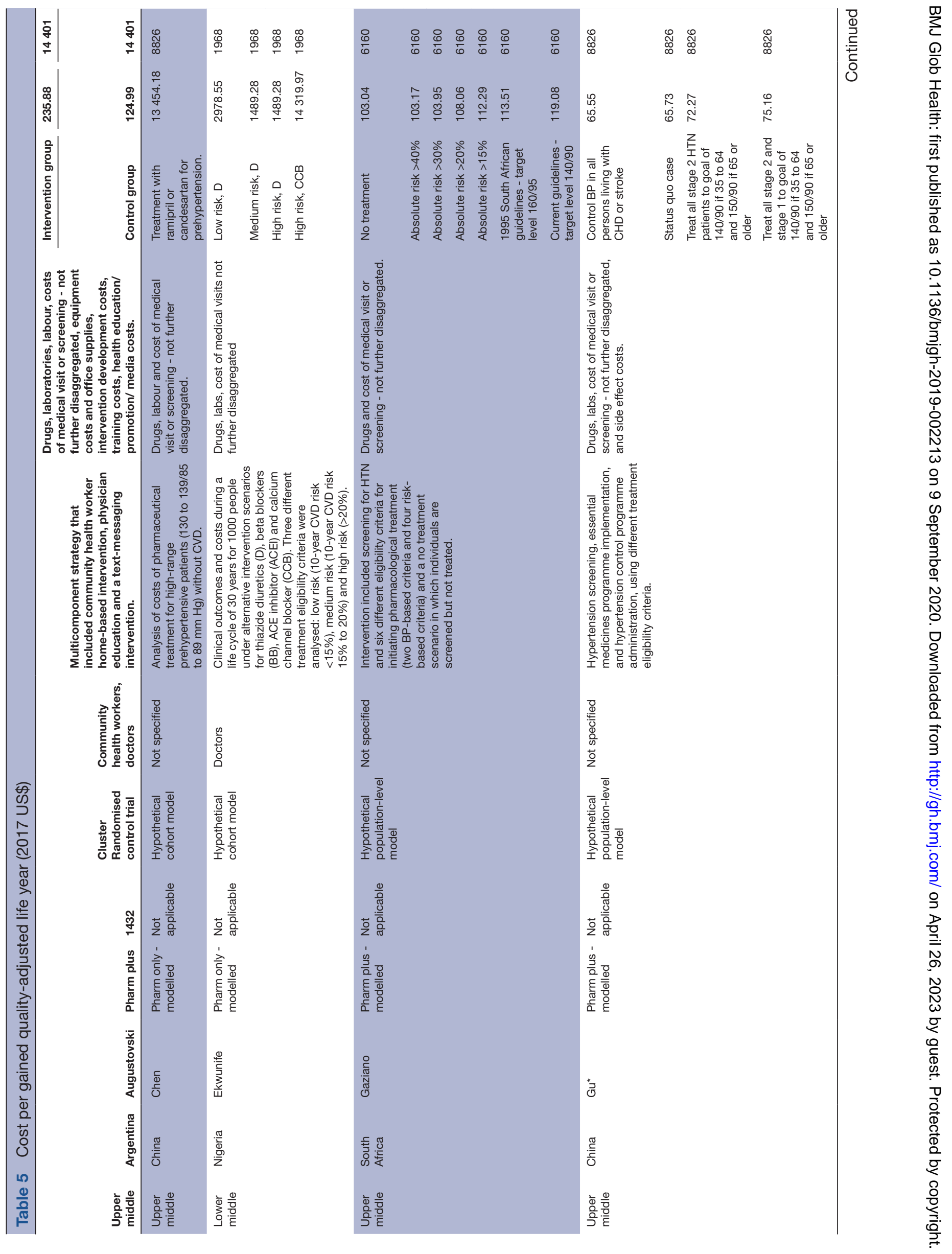




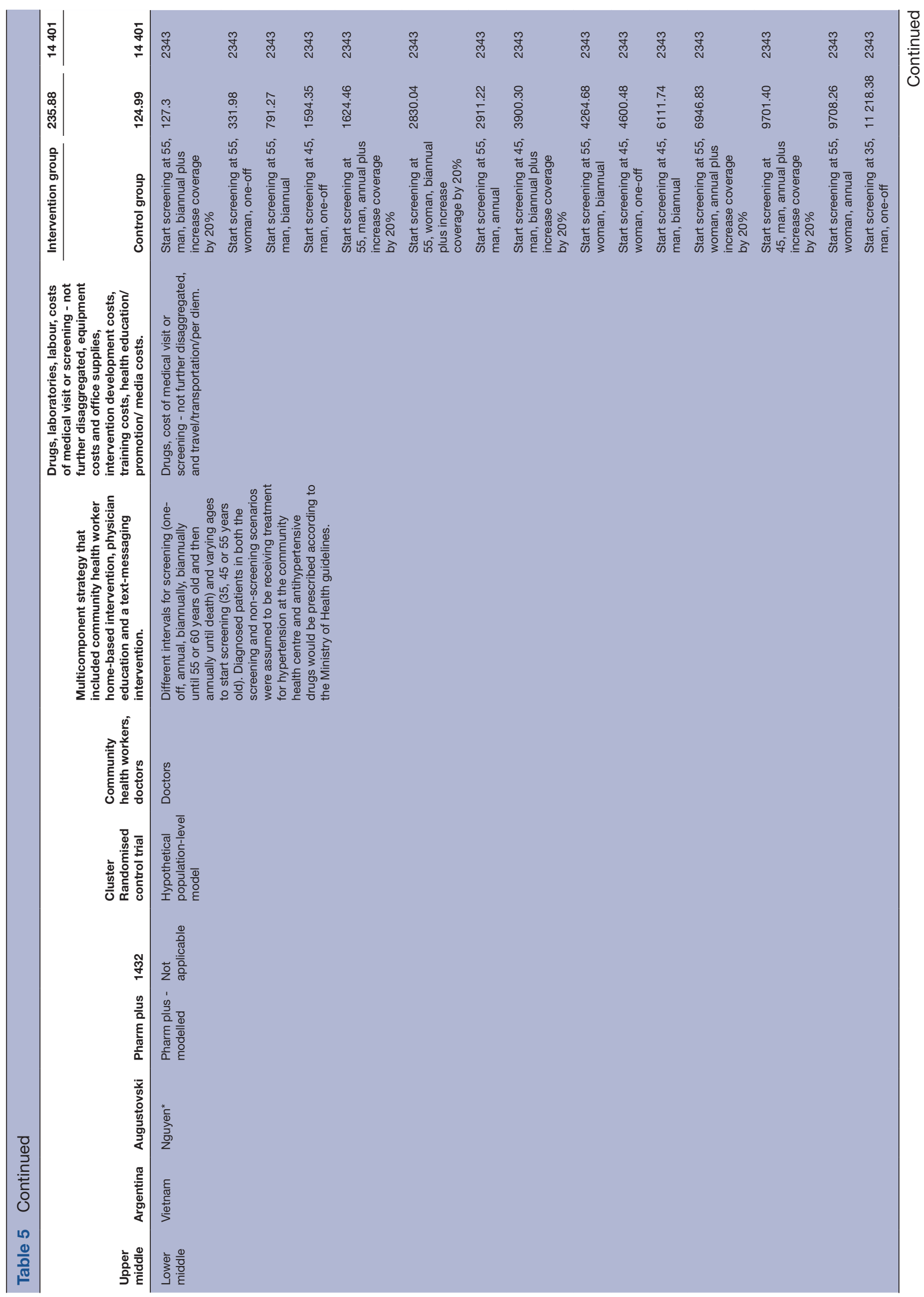

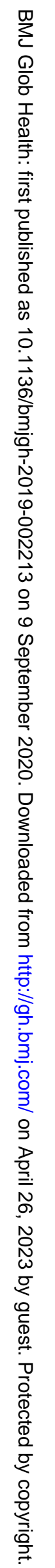




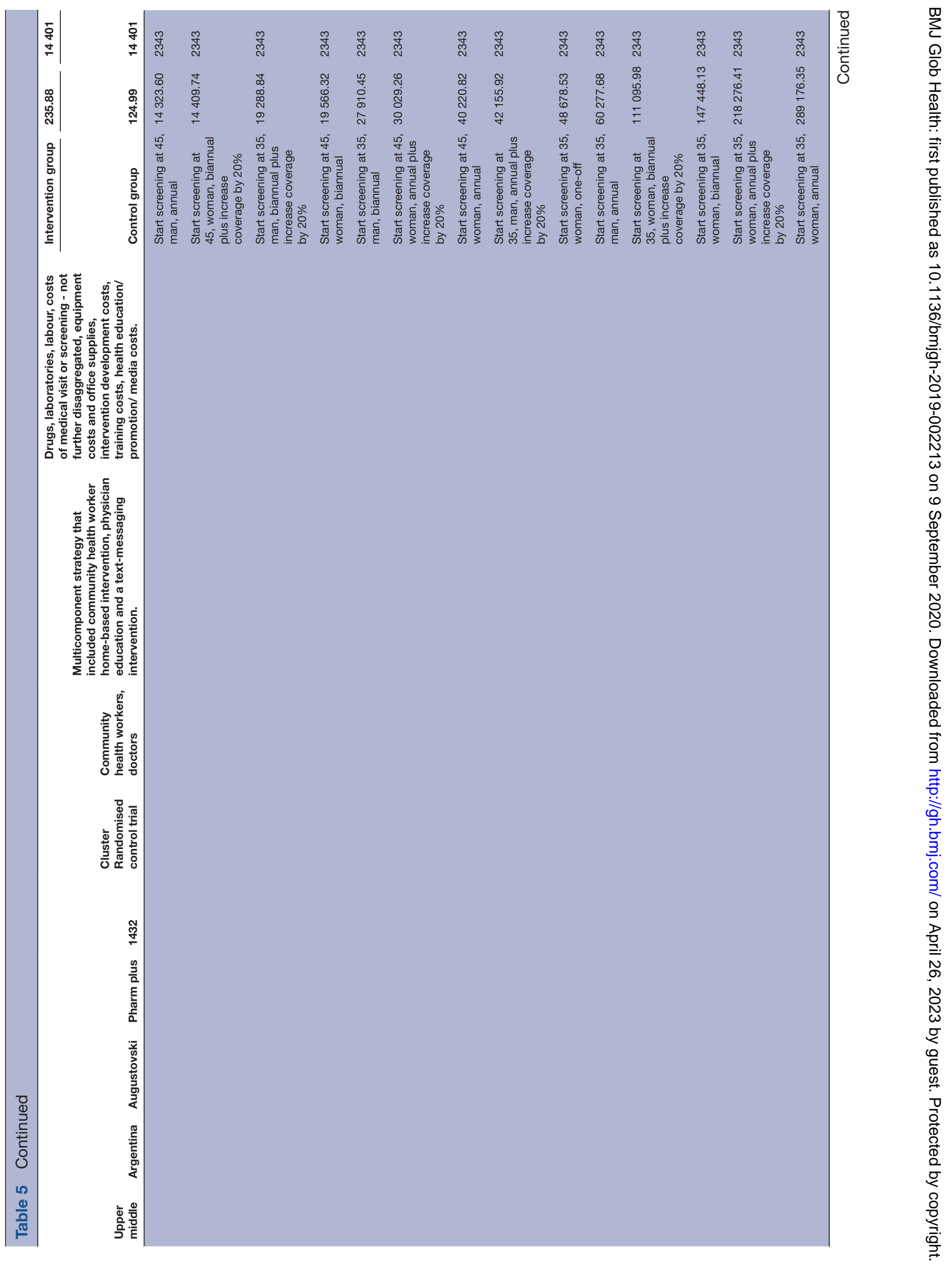




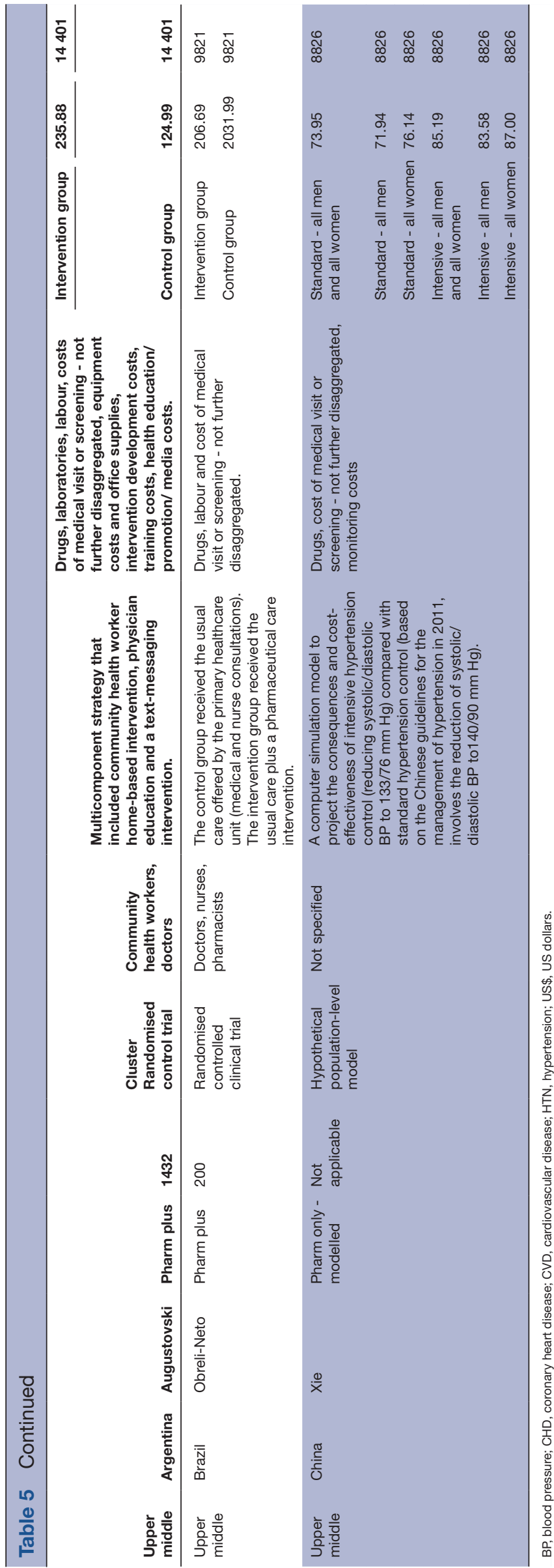

hospitals that have the capacity to perform surgery and provide inpatient care; and referral or speciality hospitals that include general specialists and provide secondary and tertiary services. As such, care was provided by a range of providers that included physicians, nurses, pharmacists and community health workers.

\section{Cost and cost-effectiveness evidence}

Study results were reported across five outcome types: Cost per $\mathrm{mm} \mathrm{Hg}$ reduction in systolic and/or diastolic blood pressure (13 studies; table 1); annual cost per patient with controlled hypertension (2 studies; table 2); annual cost per patient with hypertension (21 studies, 7 of which did not include a cost-effectiveness analysis; table 3); cost per averted DALY (14 studies; table 4); and cost per gained QALY (8 studies; table 5). Significant variability was present across studies due to cost differences even across studies with like interventions. For example, two interventions in UMICs both providing patient risk assessment, education, pharmacotherapy and adherence monitoring reported substantially different per patient costs for the intervention-US\$6.19 to US $\$ 13.38$ per patient in China (Bai et al, 2013) compared with US $\$ 203.85$ in Brazil (Cazarim and Pereira, 2018). ${ }^{24}$ In this example, the analysis in China did not include the cost of drugs whereas the analysis in Brazil included indirect costs such as the cost of absenteeism resulting from missing work for doctor's appointments. Across all the types of interventions, the range of estimates of the annual intervention cost per hypertension patient was wider in UMICs (ranging from US\$6.2 for a non-drug intervention programme in China to US\$2418 for a Pharm only programme in South Africa) than in LLMICs (ranging from US\$25.6 for a Pharm only programme in Kenya public facilities to US $\$ 987$ for a Pharm only programme in Kenya private facilities). Nonetheless, almost all studies in all countries yielded results below US $\$ 1000$ per patient for any intervention (figure 2).

Median monthly drug costs were less than US $\$ 50$ for the 23 studies with medication-specific costs of treatment by drug or drug combination group (figure 3); however, the lowest and highest monthly costs illustrate a wide range across contexts. The widest cost range was observed for monotherapy with angiotensin-converting enzyme inhibitors (ACEI) (US\$0.18 to US\$159 with a median monthly cost of US $\$ 11$ ) and beta blockers (BB) (US $\$ 0.11$ to US $\$ 153$ with a median monthly cost of US\$4.25), obtained from 13 studies for each medication type. Other commonly evaluated monotherapy plans focussed on diuretics (16 studies, with estimates ranging from US $\$ 0.12$ to US $\$ 74$ with a median of US $\$ 1.77$ ), calcium channel blockers (CCB) (14 studies, with estimates ranging from US $\$ 0.79$ to US $\$ 78$ with a median of US\$6.56) and angiotensin-II receptor blockers (ARB) (8 studies, with estimates ranging from US $\$ 1.37$ to US $\$ 73$ with a median of US\$17). Other less common treatment plans, such as multiple-drug therapies and monotherapies involving alpha blockers, alpha-2 agonists, central 


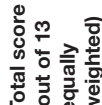

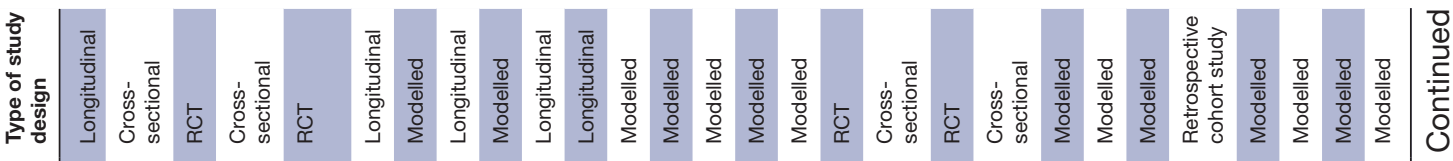

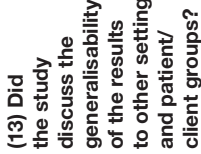

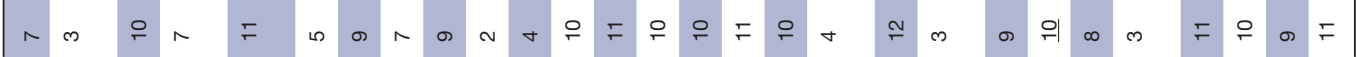

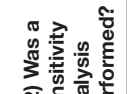

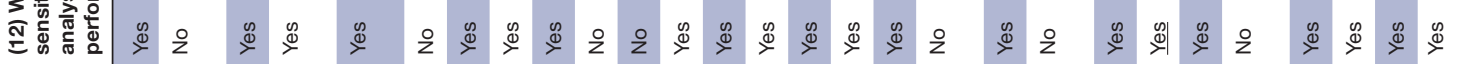

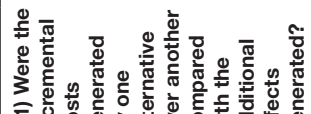

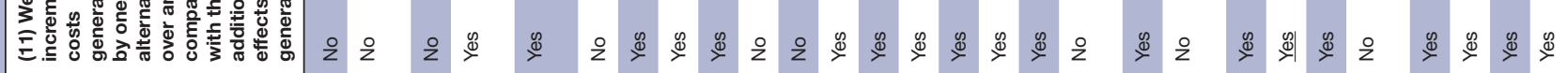

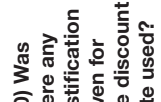

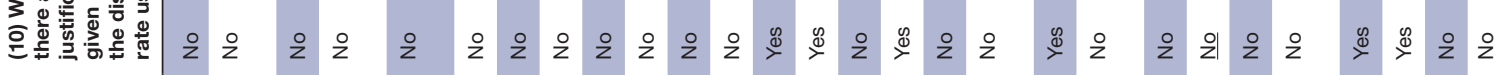

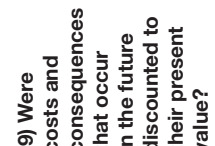

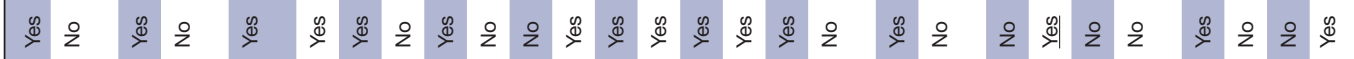

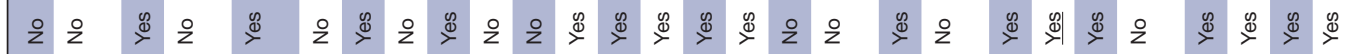

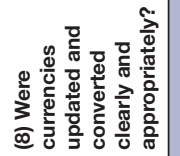

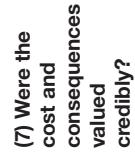

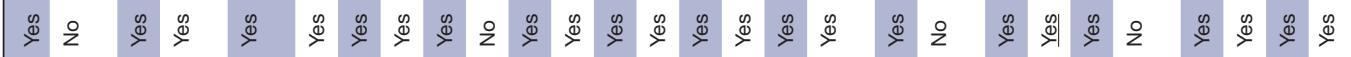

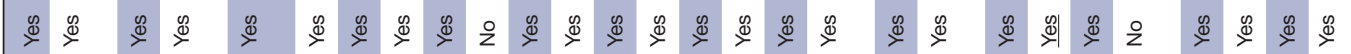

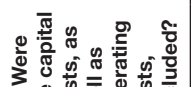

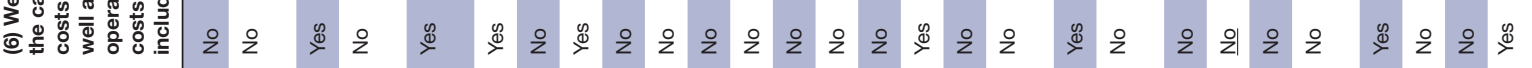

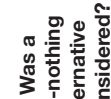

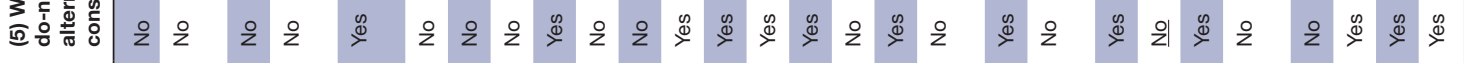

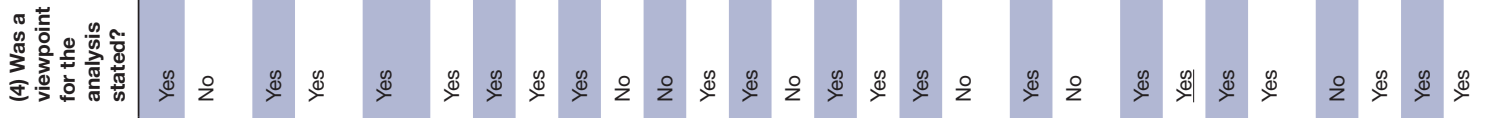

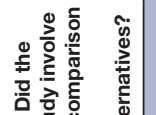

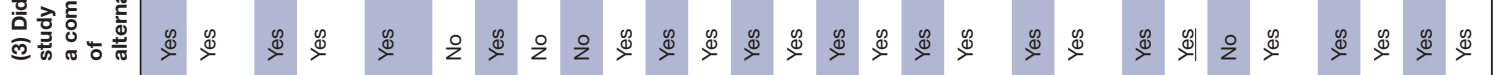

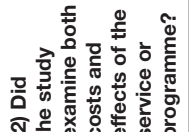

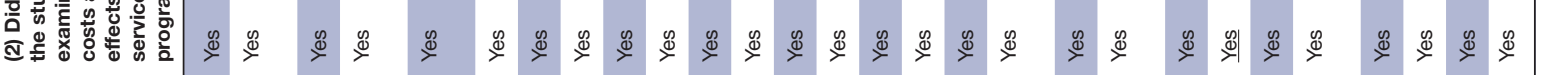

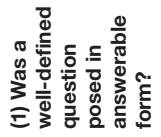

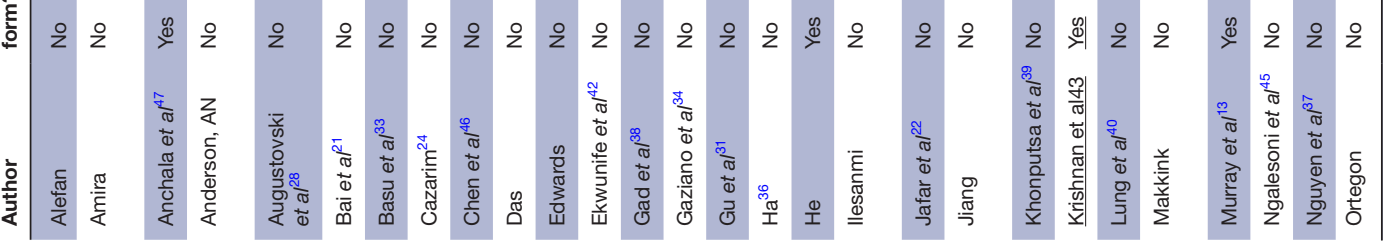




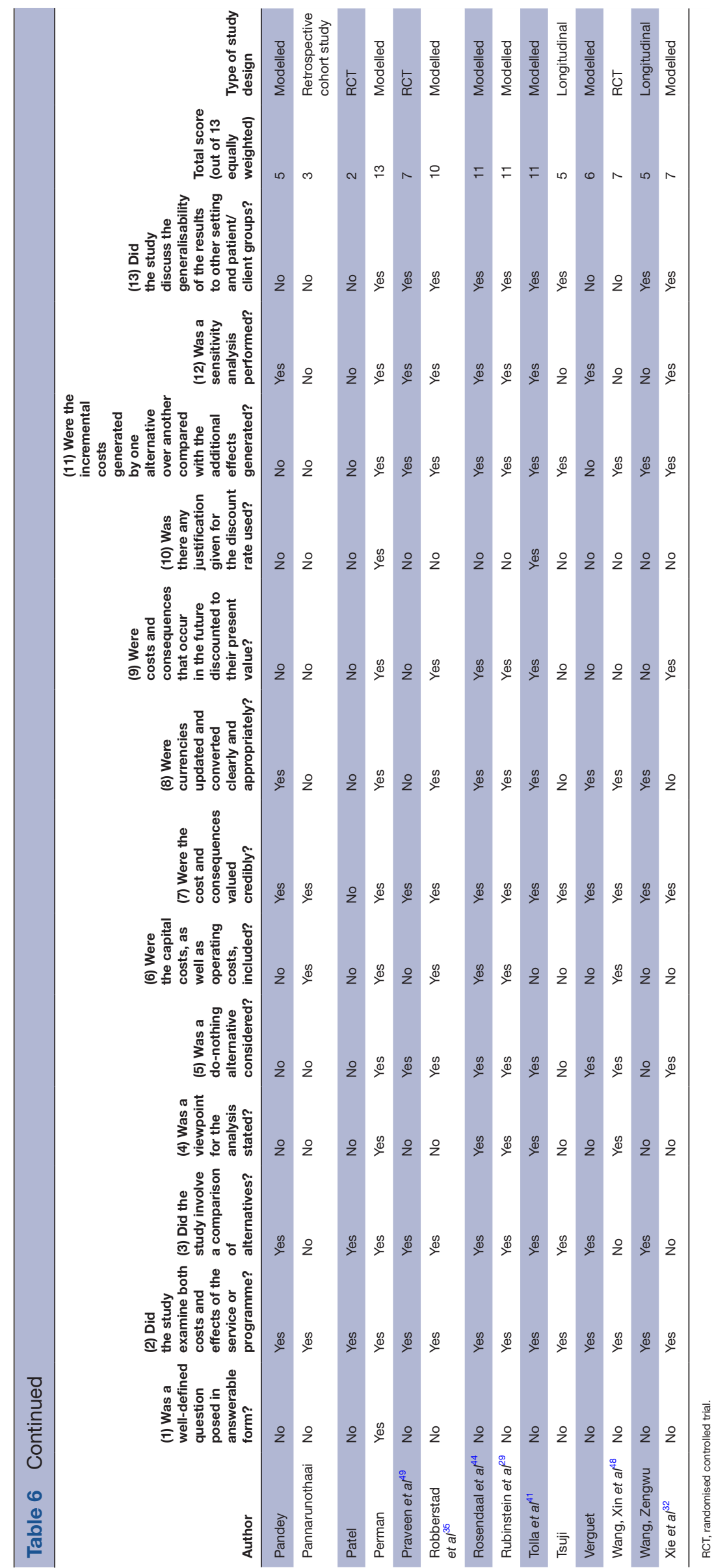

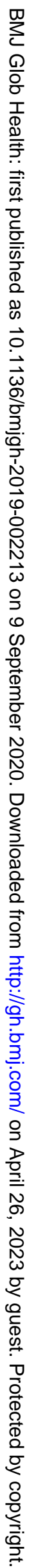




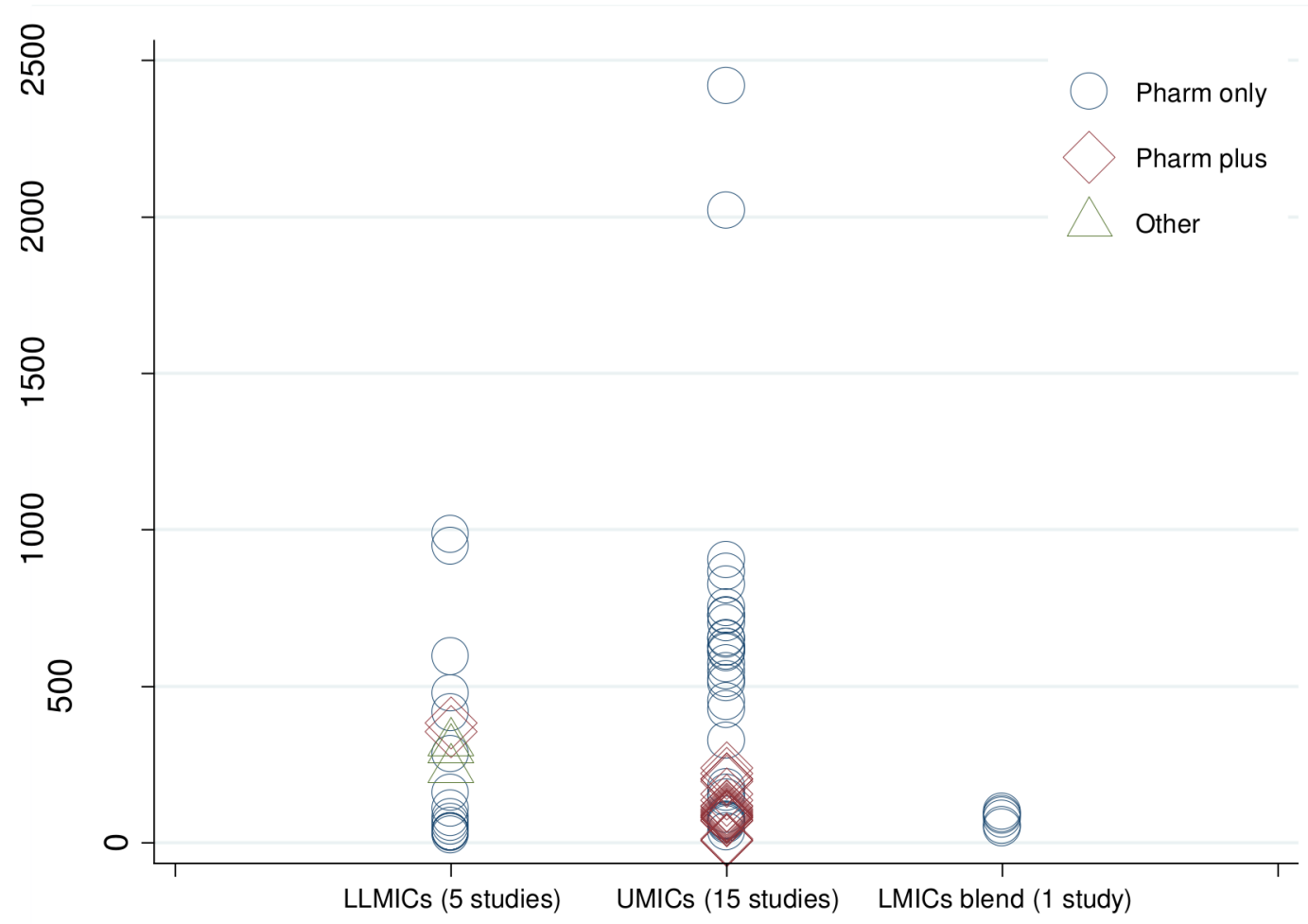

Figure 2 Annual cost per treated hypertension patient in hypertension management programmes (2017 US\$). Notes: Estimates from 21 studies. LLMICs: India, Kenya and Pakistan; UMICs: Argentina, Brazil, China, Malaysia, Mexico and South Africa. 'Pharm only' indicates interventions where pharmacotherapy is the only treatment element. 'Pharm plus' indicates combination programmes that incorporate other forms of treatment for hypertension in addition to medications. 'Other' indicates interventions that did not evaluate changes in pharmacological treatment. LMICs, low-income and middle-income countries; LLMICs, low-income and lower-middle-income countries; UMICs, upper-middle-income countries; US\$, US dollars.

acting antiadrenergics and central adrenergic inhibitors, had very limited representation with one to two studies each. Monotherapies with diuretics, BB and CCB were less costly while ACEI or ARB monotherapy incurred a higher median cost(figure 3). However, drug price variability across studies, reflecting cross-country differences in price, procurement and delivery context, prevents robust comparison of costs across treatment plans.

Of the 42 cost-effectiveness evaluations, 6 studies reported cost per averted DALY while also reporting differences across at least two CVD risk levels. Figure 4 describes the range of estimates across risk groups, in 2017 US\$. Despite the wide range of cost-effectiveness estimates, most occurred below US $\$ 1000$ per averted DALY. There was some indication that higher costeffectiveness is associated with focussing on higher-risk patients (figure 4).

A common threshold for cost-effectiveness determination in LMICs is based on per capita gross domestic product (GDP), where an intervention is considered costeffective if the cost per DALY averted or QALY gained is less than three times the annual per capita country GDP, and very cost-effective if the cost per DALY averted or QALY gained does not exceed the annual per capita GDP. Despite some limitations of the GDP threshold approach (Marseille et al, $2014^{25}$ and Bertram et al, 2016), ${ }^{26}$ we used it as a guideline to compare cost-effectiveness across studies reporting DALY-based and QALY-based costeffectiveness indicators. Hypertension interventions were found to be cost-effective in the majority of evaluations using the GDP threshold (tables 4 and 5). As figure 4 illustrates, most cost-effectiveness estimates in our review were clustered below US $\$ 1000$ per averted DALY-well below the average 2017 GDP per capita for lower-middle income countries of $\$ 2188$ (FRED, ${ }^{27}$ suggesting they could be very cost-effective for lower-middle income countries. Favourable cost-effectiveness levels using the GDP threshold were found for programmes in Argentina (Augustovski et al, $2018^{28}$ and Rubinstein et al, $2010^{29}$ ), Brazil (Obreli-Neto et al, 2015 ${ }^{30}$ ), China (Gu et al, 2015 ${ }^{31}$; Xie et al, 2018 ${ }^{32}$; Basu et al, 2016 ${ }^{33}$ ), South Africa (Gaziano et al, 2005 ${ }^{34}$ ), Tanzania (Robberstad et al, $2007^{35}$ ), Vietnam (Ha and Chisholm, 2011 ${ }^{36}$ and Nguyen et al, 2016 $6^{37}$ ), India (Basu et al, 2016 $\left.{ }^{33}\right)$, Ghana ( Gad et $a l, 2020^{38}$ ), Thailand (Khonputsa et al, 2012 ${ }^{39}$ ), Sri Lanka (Lung et al, 2019 ${ }^{40}$ ), Ethiopia (Tolla et al, 2016 ${ }^{41}$ ), Nigeria (Ekwunife et al, 2013 ${ }^{42}$ ) and Nepal (Krishnan et al, 2019. ${ }^{43}$ A small number of studies indicated that cost-effectiveness thresholds were more difficult to meet in lower-income countries; for example, cost-effectiveness was not established for select intervention scenarios reported in Nigeria (Rosendaal et al, $2016^{44}$ and Ekwunife et al, 2013) and Tanzania (Ngalesoni et al, $2016^{45}$ and Robberstad et $a l$, 2007) (table 4). Factors that were associated with not 


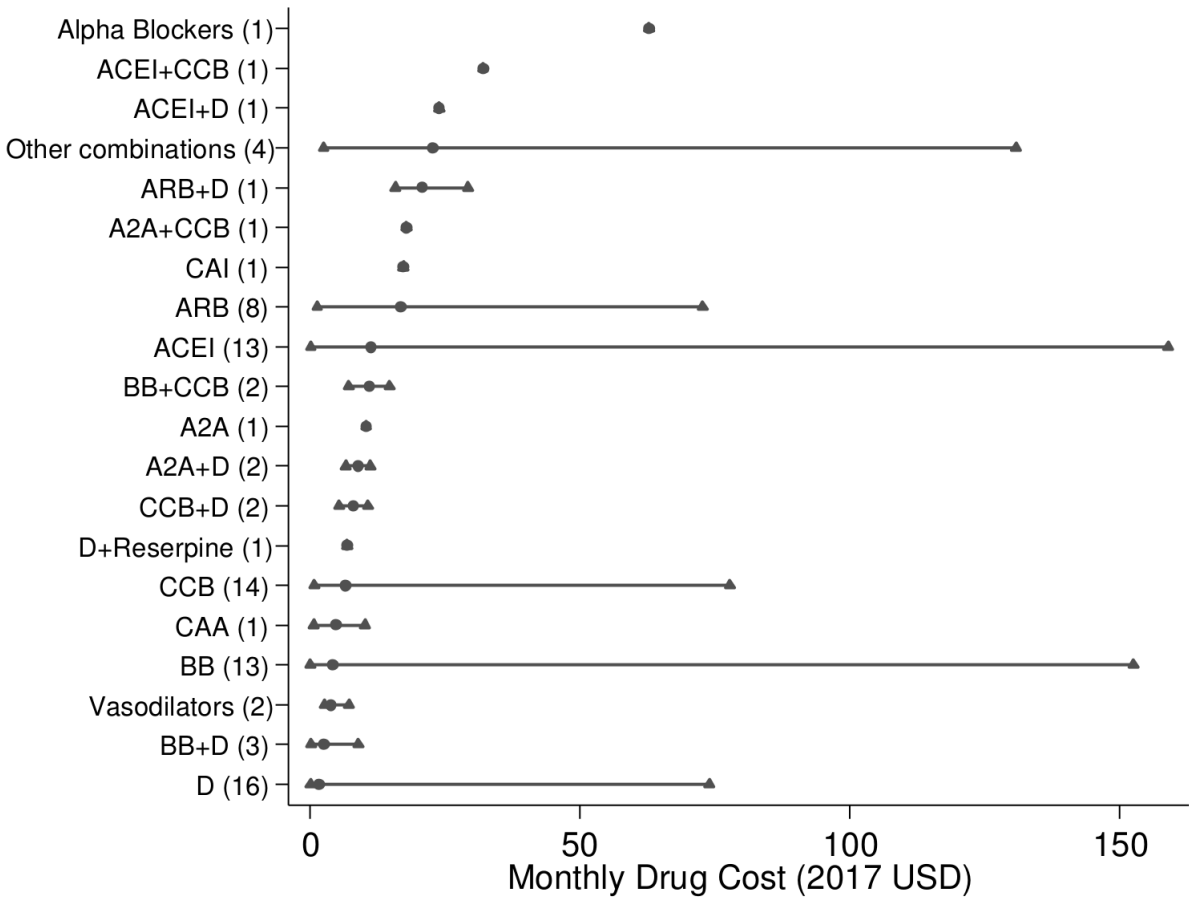

Figure 3 Range of monthly drug cost (2017 US\$) by treatment type (minimum, median, and maximum values). Notes: Estimates from 23 studies reporting costs of medication treatment only. A2A, alpha-2 agonists; ACEI, ACE inhibitors; ARB, angiotensin-2 receptor blockers; BB, beta blockers; CAA, central acting antiadrenergics; CAI, central adrenergic inhibitors; CCB, calcium channel blockers; D, diuretics; US\$, US dollars.

meeting the cost-effectiveness thresholds for their respective countries included treatment of patients at lower risk for CVD (Ekwunife et al, 2013 and Khonputsa et al, 2012), screening for hypertension at younger ages (for example, at age 35 vs 55, Nguyen et al, 2016), and addressing prehypertension (Chen et al, $2017^{46}$ (table 5).

Several studies evaluated non-pharmaceutical interventions in addition to medication treatment. One study

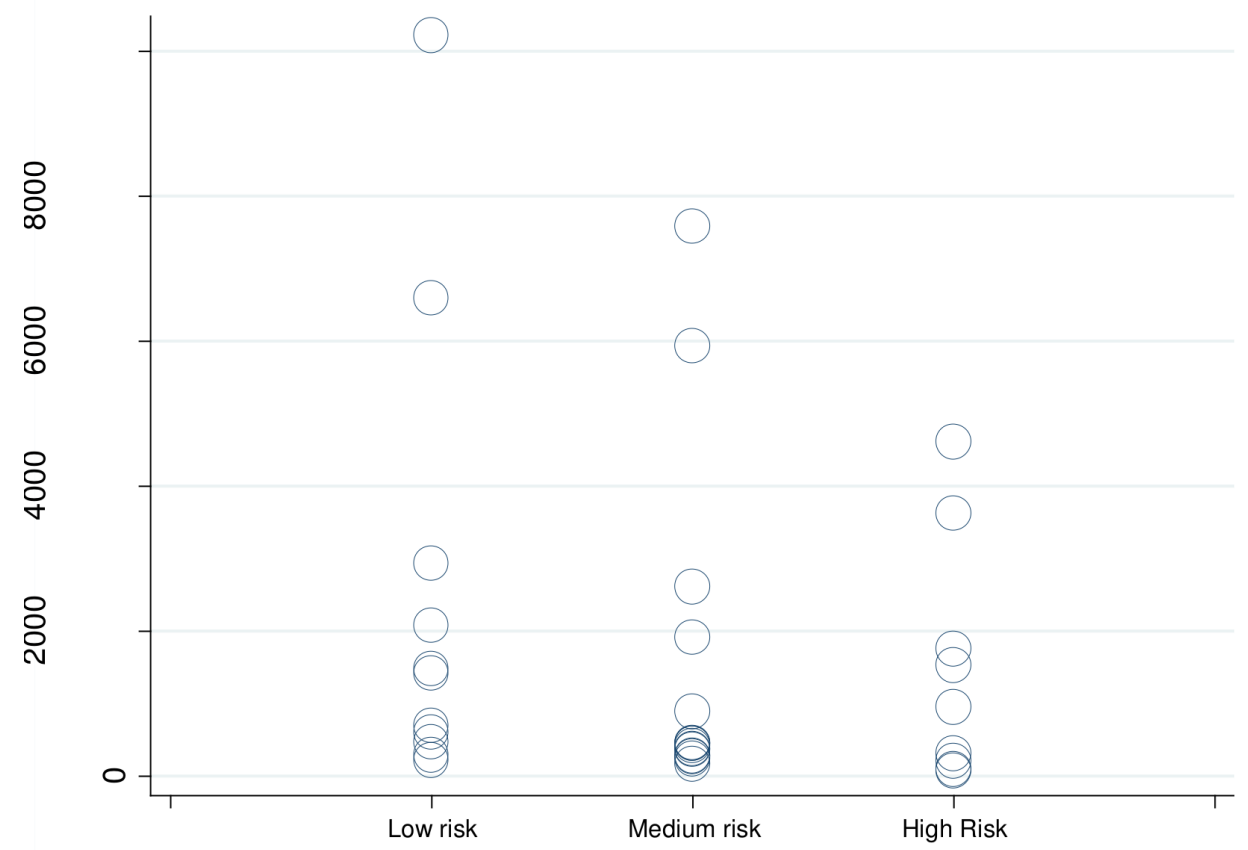

Figure 4 Cost per DALY averted, by CVD risk (in '000s 2017 US\$). Notes: Estimates from six studies reporting risk-specific estimates across multiple CVD risk levels (Basu, Ha, Khonputsa, Ngalesoni, Praveen, Tolla). CVD,cardiovascular disease; DALY, disability-adjusted life year; US\$, US dollars. 
found a complex strategy that included community health worker home-based visits, physician education and text messaging promoting lifestyle change and medication adherence was less cost-effective than usual care (Augustovski et al, 2018). By contrast, three other studies estimated that interventions for hypertension management such as physician training were more cost-effective than usual care (Anchala et al, 2015 ${ }^{47}$; Jafar et al, 2011; and Wang et al, $2013^{48}$ ).

\section{DISCUSSION}

The range of estimated costs and cost-effectiveness of hypertension programmes is wide, both across and within countries, reflecting heterogeneity in intervention design, cost components and country context. We broadly distinguished between intervention designs that involved pharmaceutical treatment only and those that included non-pharmaceutical components, such as provider or patient training, and between countries with different income levels. We did not observe clear distinctions in programme cost-effectiveness based on country group or inclusion of non-pharmaceutical programme elements; however, the large majority of interventions that reported cost per averted DALY were found to be cost-effective using national income thresholds, with costs per averted DALY not exceeding the average GDP per capita of lower-middle income nations. Some exceptions were observed in lower-income countries, where the cost-effectiveness cut-off, as defined by national GDP, is lower. This might suggest that hypertension management programmes in lower-income countries may warrant special consideration in terms of minimising costs relative to outcomes. However, the potential need to accommodate programmes in LMICs to lower cost-effectiveness thresholds is not necessarily generalisable. For example, a recent study from Nepal, a low-income country, detailed very high cost-effectiveness of a community-based hypertension management programme relative to its income threshold (Krishnan et al, 2019). Relatively higher costs per averted DALY were observed in scenarios that expanded treatment to younger age groups or to prehypertension, suggesting that more targeted treatment may improve cost-effectiveness. Median drug costs for monotherapies involving diuretics, beta blockers and calcium channel blockers appeared to be lower than those involving ACE inhibitors or combinations.

While this review did not establish a clear pattern in cost-effectiveness when comparing estimates of cost per averted DALY by patient CVD risk across studies, individual studies indicated that hypertension treatment tends to be more cost-effective when applied to populations at higher CVD risk (Ngalesoni et al, 2016; Praveen $e t$ $a l, 2018^{49}$; Ha and Chisholm, 2011; Khonputsa et al, 2012; and Tolla et al, 2016), pointing to an important area for future research on the role of risk-tailored treatment. Hypertension treatment guidelines in LLMICs can be strengthened by further evidence translating the use of simple risk assessments based on age, smoking status and obesity into population-level efficiencies in CVD prevention (Kaptoge et al, 2019). ${ }^{50}$

In addition to the low comparability across intervention programmes in LMICs, this review is subject to a number of limitations. We did not review the economic literature for the potential of behavioural modifications such as low-sodium diet, healthy weight, physical activity and eliminating tobacco use (WHO, 2011) ${ }^{51}$ to control blood pressure. Such modifications have been promoted at the population level through national policies on taxation and/or regulation of products containing trans-fatty acids, excess sodium, tobacco and added sugar and the WHO has summarised those results in online supplementary appendix 3 of the Global Action Plan for NonCommunicable Diseases (WHO, 2017 ${ }^{52}$; Task Force on Fiscal Policy for Health, 2019 $9^{53}$; and WHO, 2013 ${ }^{54}$ ). Studies in this review did not specifically aim to evaluate improved access to medications; rather, they described the relative cost-effectiveness of different treatment approaches, or, less frequently, the relative effectiveness of the same treatment approach across different study groups. Three studies that compared the cost per hypertension patient with treatment relative to no treatment found, as expected, that costs increased with the initiation of treatment (Cazarim and Pereira, 2018; Gaziano et al, 2005; and Obreli-Neto et al, 2015). This review does not assess the cost-effectiveness of populationlevel approaches that can improve hypertension and is mostly limited to studies with health-systems perspective rather than societal perspective. Programme evaluation from the health system perspective rather than the social perspective presents a narrower view of hypertension interventions. Another limiting aspect is that many studies did not specify the type of provider involved in the intervention, precluding inferences about costs associated with different provider type or delivery platform. Comparisons of drug class combinations were limited by lack of information on underlying drivers of drug price such as generic or brand status or type of drug within a drug class.

To reduce the knowledge gap about factors that can influence the cost-effectiveness of hypertension programmes, future research can focus on programme elements that may be particularly relevant to lowresource settings, such as the uptake of healthcare tasks by non-physician providers and the assessment of patient CVD risk in treatment determination. Using community health workers (CHW) in the provision of chronic disease care has been associated with increased cost-effectiveness in the USA (Kim et al, 2016 $6^{55}$ ), and has been similarly regarded in LMICs (Jeet et al, 2017 $7^{56}$ and Krishnan et al, 2019), but evidence specific to hypertension care costs is mostly lacking. Additional studies focussing on the role of CHW in improving the cost-effectiveness of hypertension interventions can help inform health strategies in areas where access to care is otherwise limited. Standardisation of cost evaluation platforms can streamline 
Table 7 Key cost elements of standardised programme implementation: WHO Global Hearts Initiative, HEARTS technical package for CVD prevention in primary care.

\begin{tabular}{|c|c|c|}
\hline $\begin{array}{l}\text { HEARTS } \\
\text { element }\end{array}$ & Description & Cost elements \\
\hline $\mathrm{H}$ : Healthy lifestyles & $\begin{array}{l}\text { Counselling on lifestyle changes, including } \\
\text { tobacco cessation, dietary modification, } \\
\text { avoiding harmful use of alcohol and } \\
\text { increasing physical activity }\end{array}$ & $\begin{array}{l}\text { Training of healthcare providers } \\
\text { Provider time for patient screening and } \\
\text { counselling } \\
\text { Health promotion materials }\end{array}$ \\
\hline $\begin{array}{l}\text { E: Evidence-based treatment } \\
\text { protocols }\end{array}$ & $\begin{array}{l}\text { Adopting simple, standard treatment } \\
\text { protocols for use in primary care for the } \\
\text { management of CVD, including secondary } \\
\text { prevention and management of high blood } \\
\text { pressure and diabetes }\end{array}$ & $\begin{array}{l}\text { Provider time for patient screening } \\
\text { Provider time for physical exam } \\
\text { Provider time for laboratory tests }\end{array}$ \\
\hline $\begin{array}{l}\text { A: Access to essential } \\
\text { medicines and technologies }\end{array}$ & $\begin{array}{l}\text { Continuous availability of essential } \\
\text { medicines and basic technology in primary } \\
\text { healthcare }\end{array}$ & $\begin{array}{l}\text { Inventory of core medicines } \\
\text { Inventory of diagnostic supplies (eg, blood } \\
\text { pressure measurement devices, laboratory } \\
\text { supplies) }\end{array}$ \\
\hline R: Risk-based Management & $\begin{array}{l}\text { Incorporating CVD risk assessment for } \\
\text { treatment and referral }\end{array}$ & $\begin{array}{l}\text { Training of healthcare providers in risk } \\
\text { assessment } \\
\text { Provider time for establishing patient risk profile } \\
\text { using risk charts }\end{array}$ \\
\hline T: Team care and task sharing & $\begin{array}{l}\text { Incorporating team-based care and non- } \\
\text { physician healthcare providers in primary } \\
\text { care }\end{array}$ & $\begin{array}{l}\text { Training of healthcare providers } \\
\text { Training of supervisors } \\
\text { Change in provider time across types of } \\
\text { healthcare providers (physicians, nurses, } \\
\text { community health workers) }\end{array}$ \\
\hline S: Systems for monitoring & $\begin{array}{l}\text { Establishing patient records for follow-up, } \\
\text { tracking and reporting health outcomes }\end{array}$ & $\begin{array}{l}\text { Technology (software, hardware) } \\
\text { Supplies (if using paper materials) } \\
\text { Administrative staff } \\
\text { Training of administrative staff }\end{array}$ \\
\hline
\end{tabular}

CVD, cardiovascular disease.

economic assessment across countries. An example of a mechanism for evaluating the costs of standardised CVD prevention approaches is provided by the costing mechanism for the HEARTS package of clinical guidelines for CVD prevention in primary care $\left(\mathrm{WHO}, 2016^{57}\right.$ and WHO, $2017^{58}$ ). A list of standard cost elements to track during implementation of hypertension management programmes is included in table 7 , which summarises the leading cost indicators of HEARTS programme components, including establishment of treatment protocols, training of healthcare providers in lifestyle counselling and risk-based management, ensuring access to essential medicines and promoting task sharing and systems for patient monitoring. Additional evidence on the costeffectiveness of introducing non-physician health workers in healthcare delivery can inform future approaches to address physician scarcity (Seidman and Atun, 2017 $7^{59}$; Jafar et al, 2011; and Chen et al, 2004 ${ }^{60}$ ).

Although CVD death rates have decreased worldwide since 1990, improvements have not been evenly distributed across countries, and have showed signs of slowing down (GBD, 2018). Both domestic and external financing for non-communicable diseases across LMICs remains low (IHME, 2019). The results of this review suggest that hypertension control approaches can be a cost-effective way to prevent premature CVD in LMICs across a variety of population, clinical and health system contexts.

\section{Author affiliations}

${ }^{1}$ Division of Global Health Protection, Centers for Disease Control and Prevention, Atlanta, Georgia, USA

${ }^{2}$ Center for Global Noncommunicable Diseases, RTI International, Seattle, Washington, USA

${ }^{3}$ Resolve to Save Lives, an initiative of Vital Strategies, New York, New York, United States

${ }^{4}$ Columbia University Irving Medical Center, New York, New York, United States ${ }^{5}$ Department of Epidemiology, Johns Hopkins Bloomberg School of Public Health, Baltimore, Maryland, USA

Contributors GS conducted a comprehensive literature search. All authors contributed to the analysis, drafting and editing of the manuscript.

Funding GS and RN received support from the CDC Foundation with funds provided by Resolve to Save Lives, a division of Vital Strategies. Resolve to Save Lives is funded by grants from Bloomberg Philanthropies; the Bill and Melinda Gates Foundation; and Gates Philanthropy Partners, which is funded with support from the Chan Zuckerberg Foundation. The funders had no role in the design of this study and did not have any role during its execution, analyses, interpretation of the data or decision to submit results. 
Disclaimer The findings and conclusions in this report are those of the authors and do not necessarily represent the official position of the Centers for Disease Control and Prevention.

\section{Competing interests None declared.}

Patient and public involvement Patients and/or the public were not involved in the design, or conduct, or reporting, or dissemination plans of this research.

Patient consent for publication Not required.

Provenance and peer review Not commissioned; externally peer reviewed.

Data availability statement Data are available upon request. As a review article, this article reports data from previously published studies.

Open access This is an open access article distributed in accordance with the Creative Commons Attribution Non Commercial (CC BY-NC 4.0) license, which permits others to distribute, remix, adapt, build upon this work non-commercially, and license their derivative works on different terms, provided the original work is properly cited, appropriate credit is given, any changes made indicated, and the use is non-commercial. See: http://creativecommons.org/licenses/by-nc/4.0/.

ORCID iD

Deliana Kostova http://orcid.org/0000-0003-2414-0166

\section{REFERENCES}

1 Chow CK, Teo KK, Rangarajan S, et al. Prevalence, awareness, treatment, and control of hypertension in rural and urban communities in high-, middle-, and low-income countries. JAMA 2013:310:959-68.

2 Ibrahim MM, Damasceno A. Hypertension in developing countries. The Lancet 2012;380:611-9.

3 Lozano R, Fullman N, Abate D, et al. Measuring progress from 1990 to 2017 and projecting attainment to 2030 of the health-related sustainable development goals for 195 countries and territories: a systematic analysis for the global burden of disease study 2017 . The Lancet 2018;392:2091-138.

4 World Health Organization. A global brief on hypertension, 2013. Available: https://www.who.int/cardiovascular_diseases/ publications/global brief hypertension/en/

5 Frieden TR, Bloomberg MR. Saving an additional 100 million lives. Lancet 2018;391:709-12.

6 Kontis V, Cobb LK, Mathers CD, et al. Three public health interventions could save 94 million lives in 25 years. Circulation 2019;140:715-25.

7 Geldsetzer P, Manne-Goehler J, Marcus M-E, et al. The state of hypertension care in 44 low-income and middle-income countries: a cross-sectional study of nationally representative individual-level data from $1 \cdot 1$ million adults. The Lancet 2019;394:652-62.

8 Roth GA, Abate D, Abate KH, et al. Global, regional, and national age-sex-specific mortality for 282 causes of death in 195 countries and territories, 1980-2017: a systematic analysis for the global burden of disease study 2017. The Lancet 2018;392:1736-88.

9 Bloom DE, Cafiero ET, Jané-Llopis E, et al. The global economic burden of noncommunicable diseases. Geneva: World Economic Forum, 2011.

10 United Nations General Assembly. Political Declaration of the highlevel meeting of the general assembly on the prevention and control of noncommunicable diseases, 2011. Available: https://digitallibrary. un.org/record/720106

11 United nations sustainable development goals. Available: https:// sustainabledevelopment.un.org/sdgs

12 World Health Organization. Noncommunicable diseases and their risk factors. third un high-level meeting on NCDS, 2018a. Available: http://www.who.int/ncds/governance/third-un-meeting/about/en/

13 Murray CJL, Lauer JA, Hutubessy RCW, et al. Effectiveness and costs of interventions to lower systolic blood pressure and cholesterol: a global and regional analysis on reduction of cardiovascular-disease risk. The Lancet 2003;361:717-25.

14 Jha P, Nugent R, Verguet S, et al. Chronic disease control. Copenhagen consensus center challenge paper, 2012. Available: https://www.copenhagenconsensus.com/sites/default/files/ chronicdisease.pdf

15 Nugent R, Brouwer E. Economic Benefit-Cost analysis of select secondary prevention interventions in LMIC. Glob Heart 2015;10:319-21.

16 Bertram MY, Sweeny K, Lauer JA, et al. Investing in noncommunicable diseases: an estimation of the return on investment for prevention and treatment services. The Lancet 2018;391:2071-8.
17 World Health Organization. Saving lives, spending less: a strategic response to noncommunicable diseases, 2018b. Available: https:// apps.who.int/iris/bitstream/handle/10665/272534/WHO-NMH-NVI18.8-eng.pdf?ua $=1$

18 Liberati A, Altman DG, Tetzlaff J, et al. The PRISMA statement for reporting systematic reviews and meta-analyses of studies that evaluate health care interventions: explanation and elaboration. PLOS Med 2009;6:e1000100.

19 Evers S, Goossens M, de Vet H, et al. Criteria list for assessment of methodological quality of economic evaluations: consensus on health economic criteria. Int J Technol Assess Health Care 2005;21:240-5.

20 Ortegón M, Lim S, Chisholm D, et al. Cost effectiveness of strategies to combat cardiovascular disease, diabetes, and tobacco use in sub-Saharan Africa and South East Asia: mathematical modelling study. BMJ 2012;344:e607.

21 Bai Y, Zhao Y, Wang G, et al. Cost-Effectiveness of a hypertension control intervention in three community health centers in China. $J$ Prim Care Community Health 2013;4:195-201.

22 Jafar TH, Islam M, Bux R, et al. Cost-Effectiveness of communitybased strategies for blood pressure control in a low-income developing country. Circulation 2011;124:1615-25.

23 Calvo-Vargas C, Padilla Rios V, Troyo-Sanromán R, et al. Reproducibility and cost of blood pressure self-measurement using the 'Loaned Self-measurement Equipment Model'. Blood Press Monit 2001;6:225-32.

24 Cazarim MdeS, Pereira LRL. Cost-Effectiveness analysis of pharmaceutical care for hypertensive patients from the perspective of the public health system in Brazil. PLoS One 2018;13:e0193567.

25 Marseille E, Larson B, Kazi DS, et al. Thresholds for the costeffectiveness of interventions: alternative approaches. Bull World Health Organ 2015;93:118-24.

26 Bertram MY, Lauer JA, De Joncheere K, et al. Cost-Effectiveness thresholds: pros and cons. Bull World Health Organ 2016;94:925-30.

27 Federal reserve bank economic data. Available: https://fred. stlouisfed.org/series/NYGDPPCAPCDLMC

28 Augustovski F, Chaparro M, Palacios A, et al. Cost-Effectiveness of a comprehensive approach for hypertension control in low-income settings in Argentina: trial-based analysis of the hypertension control program in Argentina. Value Health 2018;21:1357-64.

29 Rubinstein A, Colantonio L, Bardach A, et al. Estimation of the burden of cardiovascular disease attributable to modifiable risk factors and cost-effectiveness analysis of preventative interventions to reduce this burden in Argentina. BMC Public Health 2010;10.

30 Obreli-Neto PR, Marusic S, Guidoni CM, et al. Economic evaluation of a pharmaceutical care program for elderly diabetic and hypertensive patients in primary health care: a 36-month randomized controlled clinical trial. J Manag Care Spec Pharm 2015;21:66-75.

$31 \mathrm{Gu}$ D, He J, Coxson PG, et al. The cost-effectiveness of low-cost essential antihypertensive medicines for hypertension control in China: a modelling study. PLoS Med 2015;12:e1001860

32 Xie X, He T, Kang J, et al. Cost-Effectiveness analysis of intensive hypertension control in China. Prev Med 2018;111:110-4.

33 Basu S, Yudkin JS, Sussman JB, et al. Alternative strategies to achieve cardiovascular mortality goals in China and India: a microsimulation of target- versus risk-based blood pressure treatment. Circulation 2016;133:840-8.

34 Gaziano TA, Steyn K, Cohen DJ, et al. Cost-Effectiveness analysis of hypertension guidelines in South Africa: absolute risk versus blood pressure level. Circulation 2005;112:3569-76.

35 Robberstad B, Hemed Y, Norheim OF. Cost-effectiveness of medical interventions to prevent cardiovascular disease in a sub-Saharan African country--the case of Tanzania. Cost Eff Resour Alloc 2007;5:3.

$36 \mathrm{Ha}$ DA, Chisholm D. Cost-Effectiveness analysis of interventions to prevent cardiovascular disease in Vietnam. Health Policy Plan 2011;26:210-22.

37 Nguyen T-P-L, Wright EP, Nguyen T-T, et al. Cost-Effectiveness analysis of screening for and managing identified hypertension for cardiovascular disease prevention in Vietnam. PLoS One 2016;11:e0155699.

38 Gad M, Lord J, Chalkidou K, et al. Supporting the development of evidence-informed policy options: an economic evaluation of hypertension management in Ghana. Value Health 2020;23:171-9.

39 Khonputsa P, Veerman LJ, Bertram M, et al. Generalized costeffectiveness analysis of pharmaceutical interventions for primary prevention of cardiovascular disease in Thailand. Value Health Reg Issues 2012;1:15-22.

40 Lung T, Jan S, de Silva HA, et al. Fixed-Combination, low-dose, triple-pill antihypertensive medication versus usual care in patients with mild-to-moderate hypertension in Sri Lanka: a within-trial and 
modelled economic evaluation of the triumph trial. Lancet Glob Health 2019;7:e1359-66.

41 Tolla MT, Norheim OF, Memirie ST, et al. Prevention and treatment of cardiovascular disease in Ethiopia: a cost-effectiveness analysis. Cost Eff Resour Alloc 2016;14:10.

42 Ekwunife OI, Okafor CE, Ezenduka CC, et al. Cost-Utility analysis of antihypertensive medications in Nigeria: a decision analysis. Cost Eff Resour Alloc 2013;11:2.

43 Krishnan A, Finkelstein EA, Kallestrup P, et al. Cost-Effectiveness and budget impact of the community-based management of hypertension in Nepal study (COBIN): a retrospective analysis. Lancet Glob Health 2019;7:e1367-74.

44 Rosendaal NTA, Hendriks ME, Verhagen MD, et al. Costs and costeffectiveness of hypertension screening and treatment in adults with hypertension in rural Nigeria in the context of a health insurance program. PLoS One 2016;11:e0157925.

45 Ngalesoni FN, Ruhago GM, Mori AT, et al. Cost-Effectiveness of medical primary prevention strategies to reduce absolute risk of cardiovascular disease in Tanzania: a Markov modelling study. BMC Health Serv Res 2016;16:185.

46 Chen T, Yu D, Cornelius V, et al. Potential health impact and costeffectiveness of drug therapy for prehypertension. Int $J$ Cardiol 2017;240:403-8.

47 Anchala R, Kaptoge S, Pant H, et al. Evaluation of effectiveness and Cost-Effectiveness of a clinical decision support system in managing hypertension in resource constrained primary health care settings: results from a cluster randomized trial. J Am Heart Assoc 2015; 4:e001213.

48 Wang X, Li W, Li X, et al. Effects and cost-effectiveness of a guideline-oriented primary healthcare hypertension management program in Beijing, China: results from a 1-year controlled trial. Hypertens Res 2013;36:313-21.

49 Praveen D, Peiris D, MacMahon S, et al. Cardiovascular disease risk and comparison of different strategies for blood pressure management in rural India. BMC Public Health 2018;18:1264.

50 Kaptoge S, Pennells L, De Bacquer D, et al. World Health organization cardiovascular disease risk charts: revised models to estimate risk in 21 global regions. Lancet Glob Health 2019;7:e1332-45.
51 World Economic Forum, WHO. From burden to "best buys": reducing the economic impact of non-communicable diseases in low- and middle-income countries. Geneva: World Economic Forum, 2011. http://www.who.int/nmh/publications/best_buys_summary. pdf

52 World Health Organization. Best Buys' and Other Recommended Interventions for the Prevention and Control of Noncommunicable Diseases: Appendix 3 of the Global Action Plan for the Prevention and Control of Non-Communicable Diseases 2013-2020. Geneva: WHO, 2017.

53 Task Force on Fiscal Policy for Health. Health taxes to save lives: employing effective excise taxes on tobacco, alcohol, and Sugary beverages. chairs: Michael R. Bloomberg and Lawrence H. summers. New York: Bloomberg Philanthropies, 2019. https:// www.bloomberg.org/program/public-health/task-force-fiscal-policyhealth/

54 World Health Organization. Global action plan for the prevention and control of NCDS 2013-20. Geneva: World Health Organization, 2013.

55 Kim K, Choi JS, Choi E, et al. Effects of community-based health worker interventions to improve chronic disease management and care among vulnerable populations: a systematic review. Am J Public Health 2016;106:e3-28.

56 Jeet G, Thakur JS, Prinja S, et al. Community health workers for non-communicable diseases prevention and control in developing countries: evidence and implications. PLoS One 2017;12:e0180640.

57 World Health Organization. Hearts: technical package for cardiovascular disease management in primary health care. Geneva, Switzerland: World Health Organization, 2016. http://www.who.int/ cardiovascular_diseases/hearts/Hearts_package.pdf

58 World Health Organization. Who model list of essential medicines, 2017. Available: https://apps.who.int/iris/bitstream/handle/10665/ 273826/EML-20-eng.pdf?ua=1

59 Seidman G, Atun R. Does task shifting yield cost savings and improve efficiency for health systems? A systematic review of evidence from low-income and middle-income countries. Hum Resour Health 2017:15:29.

60 Chen L, Evans T, Anand S, et al. Human resources for health: overcoming the crisis. The Lancet 2004;364:1984-90. 